This is the peer reviewed version of the following article:

Single and multiple detections of foodborne pathogens by gold nanoparticle assays.

First published: January 2020

which has been published in final form at

https://onlinelibrary.wiley.com/doi/abs/10.1002/wnan.1584

This article may be used for non-commercial purposes in accordance with Wiley Terms and Conditions for Self-Archiving." 


\section{Single and multiple detections of foodborne pathogens by gold nanoparticle assays}

Article Type:
OPINION
OPRIMER
OVERVIEW
- ADVANCED REVIEW
FOCUS ARTICLE
SOFTWARE FOCUS

\section{Authors:}

DAKRONG PISSUWAN,,${ }^{1,2,3 *}$ CAMILLA GAZZANA ${ }^{3}$, SKORN MONGKOLSUK, $, 4,5$ and MICHAEL B. CORTIE ${ }^{3}$

Correspondence

Dakrong Pissuwan

${ }^{1}$ Materials Science and Engineering Program, Faculty of Science, Mahidol University, Bangkok, 10400 Thailand

${ }^{2}$ Nanobiotechnology and Nanobiomaterials Research Laboratory, School of Materials Science and Innovation, Faculty of Science, Mahidol University, Bangkok, 10400 Thailand ${ }^{3}$ School of Mathematical and Physical Sciences, Faculty of Science, University of Technology Sydney, NSW 2007, Australia

Email: dakrong.pis@mahidol.ac.th

\section{Funding information}

The International Research Network (IRN), Thailand Research Fund (TRF);

Grant/Award Number: IRN59W007

Australia-APEC Women in Research Fellowship 


\begin{tabular}{l} 
First author/ Correspondence \\
DAKRONG PISSUWAN* \\
${ }^{1}$ Materials Science and Engineering Program, Faculty of Science, Mahidol \\
University, Bangkok, 10400 Thailand \\
${ }^{2}$ Nanobiotechnology and Nanobiomaterials Research Laboratory, School of \\
Materials Science and Innovation, Faculty of Science, Mahidol University, \\
Bangkok, 10400 Thailand \\
${ }^{3}$ School of Mathematical and Physical Sciences, Faculty of Science, University of \\
Technology Sydney, NSW 2007, Australia \\
\hline Second author \\
CAMILLA GAZZANA \\
School of Mathematical and Physical Sciences, Faculty of Science, University of \\
Technology Sydney, NSW 2007, Australia \\
\hline Third author \\
SKORN MONGKOLSUK \\
Department of Biotechnology, Faculty of Science, Mahidol University, Bangkok 10400, \\
Thailand \\
Laboratory of Biotechnology, Chulabhorn Research Institute, Lak Si, Bangkok 10210, \\
Thailand \\
\hline Forth author \\
MICHAEL B. CORTIE \\
School of Mathematical and Physical Sciences, Faculty of Science, University of \\
Technology Sydney, NSW 2007, Australia \\
ABSTRACT
\end{tabular}

A late detection of pathogenic microorganisms in food and drinking water has a high potential to cause adverse health impacts in those who have ingested the pathogens. For this reason there is intense interest in developing precise, rapid and sensitive assays that can detect multiple foodborne pathogens. Such assays would be valuable components in the campaign to minimize foodborne illness. Here we discuss the emerging types of assays based on gold nanoparticles (GNPs) for rapidly diagnosing single or multiple foodborne pathogen infections. Colorimetic and lateral flow assays based on GNPs may be read by the human eye. Refractometric sensors based on a shift in the position of a plasmon resonance absorption peak can be read by the new generation of inexpensive optical spectrometers. Surface-enhanced Raman spectroscopy and the quartz microbalance require slightly more sophisticated equipment but can be very sensitive. A wide range of electrochemical techniques are also under development. Given the range of options provided by GNPs, we confidently expect that some, or all, of these technologies will eventually enter routine use for detecting pathogens in food.

This article is categorized under Diagnostic Tools > Biosensing

\section{KEYWORDS}

gold nanoparticles, foodborne pathogens, SERS, diagnosis, colorimetric assays 


\section{INTRODUCTION}

Pathogen contamination in food can lead to foodborne diseases. This issue is considered to be a serious human health issue worldwide, particularly for infants. Bacteria, viruses, and parasites are the most common pathogens causing foodborne diseases (Wu et al., 2018; Cacciò, Chalmers, Dorny, \& Robertson, 2018) but foodborne maladies from fungi are also known (Wu et al., 2018; Martinović et al., 2016). It is important to recognize the important role of toxins (exotoxin or endotoxin in the case of bacteria, or mycotoxins in the case of fungi) in induction of foodborne diseases (Martinović et al., 2016) because the toxins may survive food processing operations that have killed the original pathogen. Both foodborne pathogens and their toxins can be present in foods such as vegetables, fruits, eggs, dairy products, raw or undercooked/cooked products containing seafood, meat, or poultry (Paramithiotis, Drosinos, \& Skandamisal, 2017; Zhang et al., 2016; Yeni, Yavas, Alpas, \& Soyer, 2016). For example, the outbreaks of foodborne illness in Japan in 2017 were caused by norovirus that had contaminated nori (dried shredded seaweed). These outbreaks caused over 2000 people to become ill across Japan (Sakon et al., 2018). Another example was the periodic outbreaks of camplylobacteriosis and salmonellosis from consuming contaminated chicken liver in United States during 2000-2016 (Lanier, Hale, Geissler, \& Dewey, 2018). These, and many other, examples have made newspaper headlines around the world over the last decade. Various national bodies continue to seek methods to eliminate problems of this sort.

Velusamy et al. (Velusamy et al., 2010) divided the major conventional testing methods into three groups: 1) culture-and-colony counting methods, 2) immunology-based assays, and 3) the polymerase chain reaction (PCR). Recently loop-mediated isothermal amplification (LAMP) of DNA has also come to the fore (Niessen, Luo, Denschlag, \& Vogel, 2013). Although these methods can work well, they also have disadvantages. They may be time consuming ( $2-10$ days), or labor intensive, or high cost (Velusamy et al., 2010). Typically, these techniques require a long pre-enrichment period without using any selective medium. In addition, the culture-and-colony method may be unreliable in some cases because some pathogens such as Campylobacter have a complex requirement for their growth (Hinton, 2016). In contrast, the LAMP method is becoming increasingly dominant in many countries due to its speed and low limit of detection $\left(10 \mathrm{CFU} \mathrm{mL} \mathrm{m}^{-1}\right.$ to $\left.1000 \mathrm{CFU} \mathrm{mL} \mathrm{mL}^{-1}\right)$ even though it is still relatively expensive to apply. Nevertheless, because no single method is able to meet all criteria, there continues to be an interest in developing alternative detection methods that might have increased sensitivity, or that might be quicker or cheaper than the classical methods.

In the present review we will consider the role that analytical techniques based on gold nanoparticles (GNPs) can play in the detection of foodborne pathogens. This is a narrower scope than some other recently published reviews, for example those of Mocan et al. (Mocan et al., 2017). Yoo and Lee (Yoo \& Lee, 2016), and Niessen et al. (Niessen, Luo, Denschlag, \& Vogel, 2013), which considered the problem of detecting pathogens either more broadly or by techniques that did not 
involve GNPs. Here we include any nanoscale gold nanoparticle - sphere, shell, rod, cube, star etc. within our definition of GNPs. GNPs offer a technologically interesting array of properties: they are non-toxic, readily synthesized, almost chemically inert, very small, electron-dense, and have a strongly enhanced optical absorption (at a wavelength of $\sim 520 \mathrm{~nm}$ in the case of nanospheres). Furthermore, the shape of the nanoparticles can be controlled during synthesis so that specialized geometries, such as nanorods, can be made. The peak optical absorbance of nanorods and other nonspherical gold particles is red-shifted from the $\sim 520 \mathrm{~nm}$ of spheres towards the near-infra red (NIR). It is particularly the strong and tunable optical absorptance peak of GNPs that allow them to be used in various kits (Shehata \& Hadi, 2018) for the expanding medical diagnostics industry but here we focus only on their use in the detection of food pathogens.

\section{COMMON FOODBORNE PATHOGENS}

As mentioned previously, bacteria, viruses, and parasites are common foodborne pathogens. Examples of foodborne pathogenic bacteria include Campylobacter jejuni, Listeria monocytogenes, Samonella spp., Shigella spp., Escherichia coli O157:H7, Clostridium botulinum, Clostridium perfringens, Staphylococcus aureus, Vibrio cholera, and Bacillus cereus (Hounmanou et al., 2016; Cho \& $\mathrm{Ku}, 2017)$. The common foodborne virus is Hepatitis E virus (HEV) and this is especially of concern in developing countries (Seo et al., 2014). Poor sanitation of food preparation, particularly of meat products, can lead to HEV infection resulting in liver disease (Slot et al., 2017). The major parasites involved in foodborne diseases include Cryptosporidium, Trichinella, and Toxoplasma (Cacciò, Chalmers, Dorny, \& Robertson, 2018; Algaba et al., 2018). Examples of foodstuffs that are commonly contaminated and which may cause foodborne diseases are shown in Table 1.

Even if live pathogens are no longer present, there is the question of toxins that might be left behind by the pathogen. In particular, endotoxin and exotoxin can play a role during the outbreak of foodborne diseases. Endotoxin is found in gram negative bacteria. This toxin is located at the lipid part of lipopolysaccharide (LPS) and may be released if the bacterium dies. In contrast, exotoxin can be released from living bacterial cells; mostly gram positive bacteria. For example, Staphylococcus aureus can release a food poisoning exotoxin known as staphylococcal enterotoxin (Fletcher et al., 2015), and Listeria monocytogenes produces and releases listeriolysin $\mathrm{O}$ which acts as a hemolysin that has an ability to destroy red blood cells (Binh, Minh, \& Nguyet, 2017). 
TABLE 1 Examples of pathogenic bacteria, viruses, and parasites that can contaminate food and cause foodborne diseases.

\begin{tabular}{|c|c|c|}
\hline $\begin{array}{c}\text { Pathogenic } \\
\text { bacteria/virusesparasites }\end{array}$ & Main contaminated foods & Foodborne diseases \\
\hline Campylobacter jejuni & Chicken & $\begin{array}{l}\text { Campylobacteriosis (Huang et } \\
\text { al., 2018) }\end{array}$ \\
\hline Listeria monocytogenes & $\begin{array}{l}\text { Seafood, meats, dairy products, } \\
\text { and vegetables }\end{array}$ & $\begin{array}{l}\text { Listeriosis (Jemmi \& Stephan, } \\
\text { 2006) }\end{array}$ \\
\hline Salmonella spp. & Eggs and egg products & $\begin{array}{l}\text { Tyhphoid fever, Salmonellosis } \\
\text { (Pal et al., 2015; ESFA, 2017; } \\
\text { Zhao et al., 2017) }\end{array}$ \\
\hline Shigella spp. & $\begin{array}{l}\text { Potato salad, ground beef, raw } \\
\text { oyster, fish, and raw vegetables }\end{array}$ & $\begin{array}{l}\text { Shigellosis (Warren, Parish, \& } \\
\text { Schneider, 2006) }\end{array}$ \\
\hline $\begin{array}{l}\text { Escherichia coli } \quad \text { (E. coli }) \\
\text { O157:H7 }\end{array}$ & Hamburger, ground beef & $\begin{array}{l}\text { Food poisoning (Pollari et al., } \\
\text { 2017) }\end{array}$ \\
\hline Clostridium botulinum & Canned foods & Botulism (Kalluri et al., 2003) \\
\hline Clostridium perfringens & Meat products & $\begin{array}{l}\text { Human gas gangrene, Type A } \\
\text { diarrhea, and Type C human } \\
\text { necrotic enteritis (Brynestad \& } \\
\text { Granum, 2002; Granum, 1990; } \\
\text { Duncan, 1970) }\end{array}$ \\
\hline Staphylococcus aureus & $\begin{array}{l}\text { Sliced meat, meat products, } \\
\text { salads, pastries, custards, raw } \\
\text { milk, and chees }\end{array}$ & $\begin{array}{l}\text { Staphylococcal food poisoning } \\
\text { (Pillsbury, Chiew, Bates, \& } \\
\text { Sheppeard, 2013) }\end{array}$ \\
\hline Vibrio cholera & Seafood & $\begin{array}{l}\text { Severe watery diarrhea (Boyce } \\
\text { et al., 1995; Hill et al., 2011) }\end{array}$ \\
\hline Bacillus cereus & $\begin{array}{l}\text { Milk, meats (diarrhoeal type) } \\
\text { Rice, pasta (emetic type) }\end{array}$ & $\begin{array}{l}\text { Food poisoning: diarrhoeal } \\
\text { type and the emetic type } \\
\text { Granum \& Lund, 1997; } \\
\text { Tewari \& Abdullah, 2015) }\end{array}$ \\
\hline Hepatitis E virus & Meat products & $\begin{array}{l}\text { Liver disease (Yugo \& Meng, } \\
\text { 2013) }\end{array}$ \\
\hline Norovirus $(\mathrm{NV})$ & Bivalve molluscs & $\begin{array}{l}\text { Food poisoning: vomiting, } \\
\text { abdominal cramps, fever, } \\
\text { watery diarrhoea, headache, } \\
\text { chills and myalgia (Liu et al., } \\
\text { 2015; Sala et al., 2009) }\end{array}$ \\
\hline Cryptosporidium spp. & Salad bar, ice & $\begin{array}{l}\text { Cryptosporidiosis intestinal } \\
\text { disease) Cacciò, Chalmers, } \\
\text { Dorny, \& Robertson, 2018; } \\
\text { Costa et al., 2018) }\end{array}$ \\
\hline Trichinella spp. & Sausages, dried meat & $\begin{array}{l}\text { Trichinosis Cacciò, Chalmers, } \\
\text { Dorny, \& Robertson, 2018; } \\
\text { Purslow, 2016) }\end{array}$ \\
\hline Toxoplasma gondii & Meat & $\begin{array}{l}\text { Toxoplasmosis (Algaba et al., } \\
\text { 2018; Saheb, 2018) }\end{array}$ \\
\hline
\end{tabular}




\section{PROPERTIES OF GNPS RELEVANT TO DIAGNOSIS}

\subsection{General properties of gold nanoparticles}

Gold nanoparticles (GNPs) are widely used across the biomedical field due to their biocompatibility arising from their high chemical and physical stability, ease of functionalization with biologically active and organic molecules, and their unique optical properties resulting from the collective oscillation of electrons located in the conduction bands. The absorption peak caused by the latter is known as a localized surface plasmon resonance (LSPR) (Figure 1) (Amendola et al., 2017) and is frequently exploited in diagnostic technologies. These oscillations occur when light of a resonant frequency impinges on the GNP. They lead to electrical polarization of the GNP, forming (in the simplest case) an oscillating dipole that absorbs or scatters the light (Cordeiro et al., 2016).

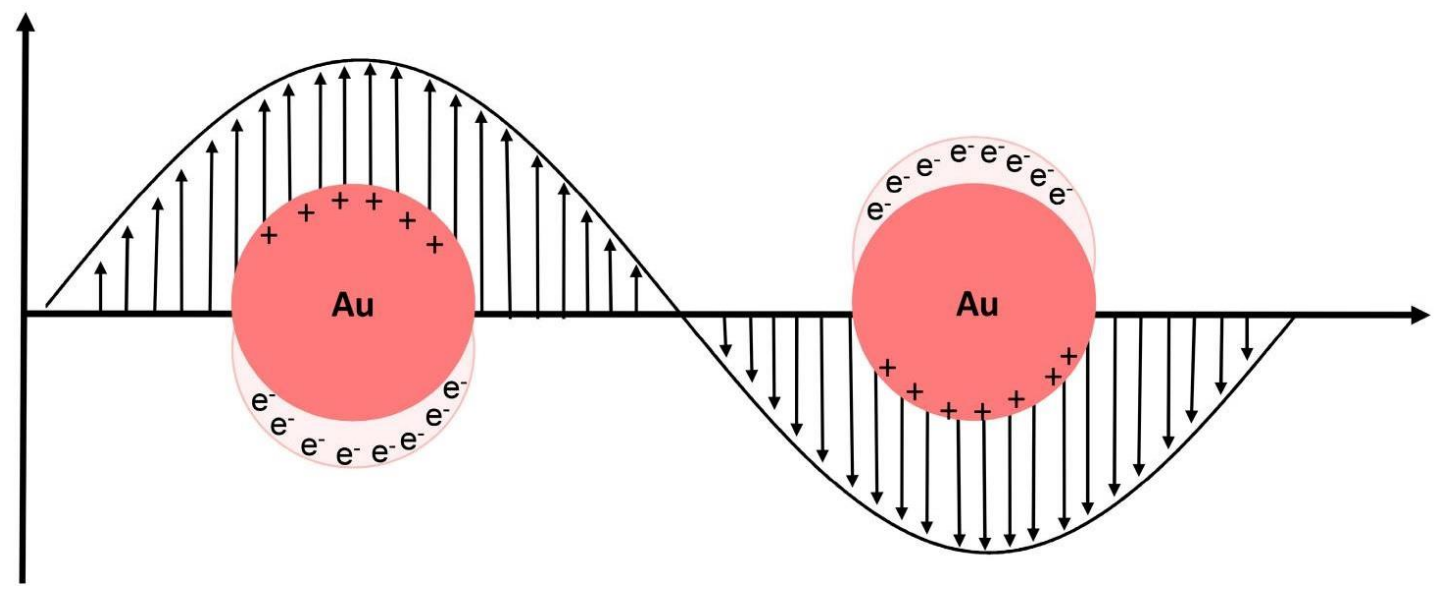

FIGURE 1 Representation of surface electrons of GNPs interacting with electromagnetic waves to induce localized surface plasmon resonance (LSPR) (Cordeiro et al., 2016). Reprinted with permission from Ref. (Cordeiro et al., 2016). Copyright $\odot 2016$ Multidisciplinary Digital Publishing Institute.

The frequency and strength of the LSPR is strongly influenced by the GNP's shape and size, the interparticle distance and the dielectric constant of the surrounding medium. It is possible to selectively modify one or more of these variables to fine-tune the LSPR for different applications. An LSPR may involve both scattering and absorption phenomena. Generally, the use of smaller and more symmetrical GNPs favors absorption while larger and more anisotropic shaped GNPs tend to favor scattering (Cordeiro et al., 2016).

Many sizes and shapes of GNPs can be synthesized, including nano-cubes, prisms, stars, octahedrons, rods, plates, and less well-defined shapes like flowers (Du et al., 2018; Fkiri et al., 2017). Colloids of spherical GNPs of $<60 \mathrm{~nm}$ diameter have a characteristic ruby red color in aqueous solution due to an LSPR-induced absorption peak at about $520 \mathrm{~nm}$. This results in the 
absorption of green light so that the light that is transmitted appears red or burgundy to the eye. However, as symmetry is reduced and the GNP becomes more anisotropic (eg. gold nanorods (GNRs)), an additional LSPR band appears at longer wavelengths. This can be tuned into the nearinfrared (NIR) by an increase of the aspect ratio of the nanorods (Carnovale, Bryant, Shukla, \& Bansal, 2016). Fine tuning of the optical properties of GNPs is essential for optimizing their performance in a variety of applications: optical properties that maximize absorption are ideal for photothermal therapies or colorimetric assays while those that favor scattering are more suited for in vivo imaging using NIR (Cordeiro et al., 2016) or surface-enhanced Raman spectroscopy (Qian et al., 2008) (Figure 2). Diagnostic applications of GNPs most commonly use spherical particles.

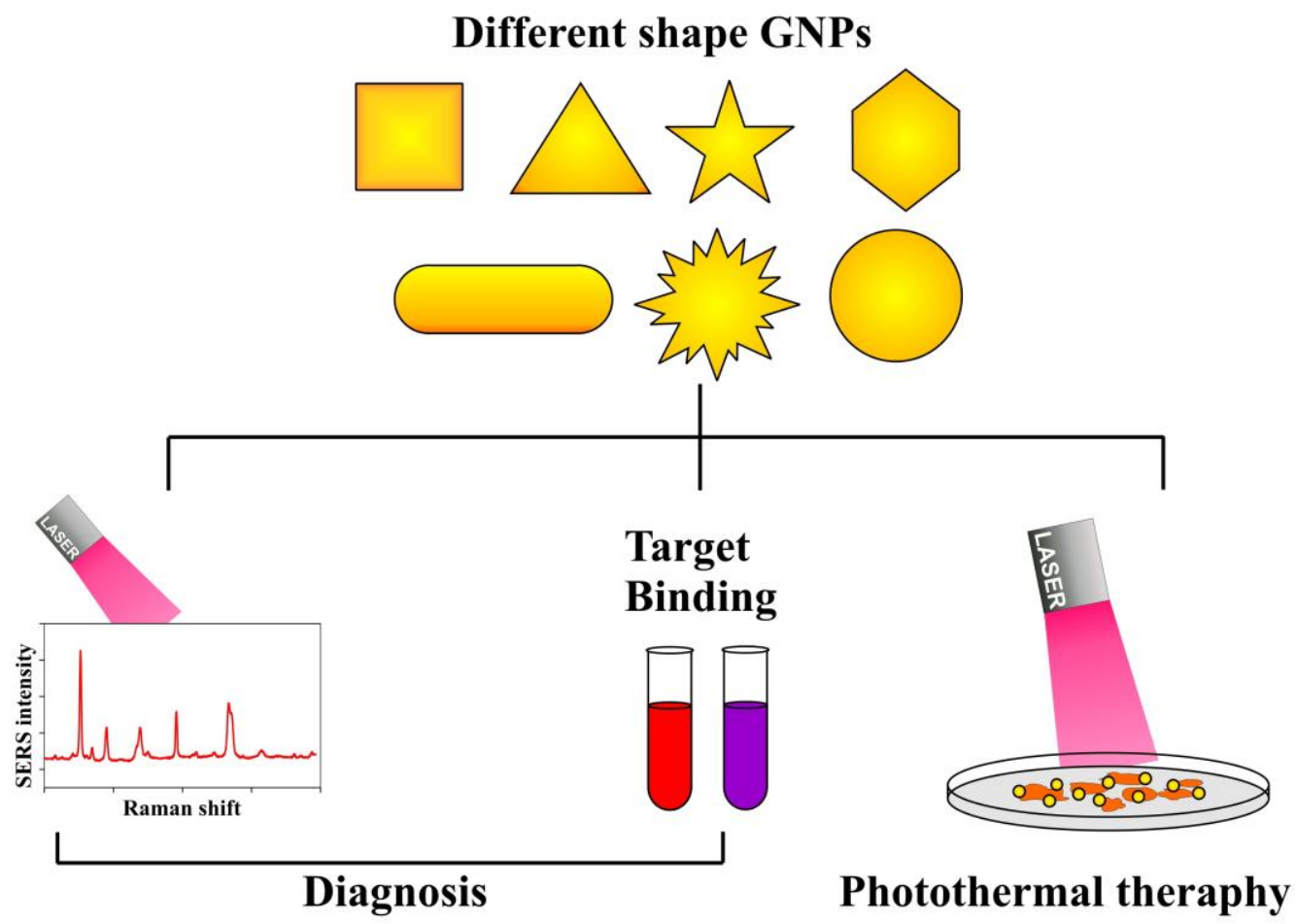

FIGURE 2 Schematic diagram showing the use of GNPs in various forms of biomedical applications.

Synthesis of GNPs can be split into two categories: a 'bottom-up' synthetic approach involving the reduction of $\mathrm{Au}^{3+}$ ions and the consequent precipitation of GNPs in the form of spheres, rods or polygons, and the 'top-down' approach involving the spatially-directed delivery (or removal) of Au to form a desired nanostructure, such as a nano-bowtie or array of triangles. Currently, most of the diagnostic applications using GNPs favor the bottom-up approach. In this case GNPs can be synthesized via chemical or electrochemical reduction, possibly assisted by thermal or sonochemical means (Eustis \& El-Sayed, 2006). The chemical method is most common, utilizing a reducing and stabilizing agent. One of the most renowned chemical methods for synthesis of spherical GNPs is the 
Turkevich method involving the reduction of $\mathrm{HAuCl}_{4}$ by citrate ions in water (Turkevich, 1985). In this instance, the trisodium citrate dihydrate acts as both the reducing agent and stabilizer, resulting in a colloid of spherical GNPs with a characteristic burgundy color. Importantly, the synthesis process leaves the surface of the GNPs both coated with citrate ions and negatively charged (Spina et al., 2017). This stabilizes the GNPs as a colloid. Electrochemical synthesis of GNPs involves the reduction of gold metal ions in the presence of surfactants in a simple two-electrode cell. This process can, for example, be used to deposit GNPs on the surfaces of multi-walled carbon nanotubes, in high quality and with controllable yields (Herizchi, Abbasi, Milani, \& Akbarzadeh, 2016). Ionic liquids can also be used to synthesize GNPs, acting as the solvent, capping agent, template, and precursor simultaneously. When ionic liquids are used in the sonochemical synthesis of GNPs it becomes possible to synthesize very small NPs with a fast rate of reaction, however the size distribution is often wide. Increased control over size distribution and shape can be achieved through the addition of surfactants (Herizchi, Abbasi, Milani, \& Akbarzadeh, 2016).

Synthetic methods that use biologically-derived reductants are sometimes reported in the literature. The motivation is generally that the resulting GNPs ought not to require subsequent detoxification processes before use because 'natural products' were used in their manufacture. So-called 'biological' synthetic methods may involve the use of plants, plant extracts, enzymes or even synthesis within live microorganisms (Du et al., 2018; Herizchi, Abbasi, Milani, \& Akbarzadeh, 2016). The argument for the use of such natural products as reactants is weakened however by the fact that a synthetic form of the relevant reductant or surfactant would normally be commercially available at a greater purity and possibly at lower cost than the ill-defined mixture of 'biologically-sourced' reductants and surfactants. In any case, from the point-of-view of diagnostic applications, it is far better to use well-characterized and high purity synthetic reductants and surfactants in the preparation of GNPs as the 'toxicity' issue does not even arise in ex situ tests.

\section{SINGLE DETECTION OF FOODBORNE PATHOGENS}

As we will discuss below, there are several GNP-based techniques that are suitable for detection of a single pathogen. Each has its advantages and disadvantages and none dominates yet in the marketplace. It is still an open question whether any of these techniques can displace the industrystandard colony or DNA-based techniques in routine commercial test work.

\subsection{Solution-based colorimetric assays using GNPs}

Manipulation of the LSPR causes color changes to colloids of GNPs that can be readily detected. As a result, GNPs have been used as a nanoprobe platform that is flexible enough to detect both target molecules at very low concentrations (Elghanian et al., 1997) and whole pathogens (Verma, 
Rogowski, Jones, \& Gu, 2015). Here, we focus on application of this technology to detect specific foodborne pathogens.

Early detection of contaminated food by using a solution-based colorimetric assay that employs GNPs can be achieved without using sophisticated equipment. This type of assay can utilize the strong absorption and light scattering properties of GNPs that were described above. GNPs have extinction coefficients that are $>1000$ times higher than organic dyes, and the colorimetric changes display high sensitivity (Niu et al., 2014) and can often be detected by the naked eye (Du et al., 2018; Bui, Ahmed, \& Abbas, 2015; Kim et al., 2018; Li et al., 2018). In order to achieve specificity towards foodborne pathogens of interest, targeting moieties such as antibodies (Bui, Ahmed, \& Abbas, 2015), oligonucleotides (Du et al., 2018), or aptamers (Niu et al., 2014; Kim et al., 2018; Ma et al., 2017) can be conjugated to the surfaces of GNPs. For example, Ma et al. (Ma et al., 2017) developed a GNP aptasensor for detecting Salmonella typhimurium, a common cause of food-associated illnesses. Aptamers are short, specific oligonucleotide or single stranded DNA (ssDNA) sequences. These can be absorbed onto the surface of GNPs and will prevent aggregation of the GNPs. However, in the presence of their specific targets, aptamers preferentially desorb from GNPs and bind their targets, leading to GNP aggregation. Based on this principle, S. typhimurium could be detected at $56 \mathrm{CFU}$ $\mathrm{mL}^{-1}$. In a slightly different approach, isothermal recombinase polymerase amplification (RPA) was used in combination with unmodified GNPs by Chen et al to detect Salmonella in milk. A detection limit of $50 \mathrm{CFU}$ was demonstrated after 6 hours enrichment.

Aptamers have also been used to detect Campylobacter jejuni and Campylobacter coli in chicken carcass samples using a two-stage aptasensor platform (Figure 3) (Kim et al., 2018). In the first stage, samples are enriched for $48 \mathrm{~h}$, whilst in the second stage (detection) GNPs either remained red in the absence of target pathogens or they aggregated and produced a purple color if pathogens were present. This aptasensor was found to be comparable in accuracy to the current 'gold-standard' tazobactamsupplemented culturing method and superior to official agar detection methods which can take 4-8 days to complete. Although this colorimetric assay does not allow for the quantification of $C$. jejuni or C. coli, it can be used on real food samples and gives an easily detectable result within 30 min after only $48 \mathrm{~h}$ of sample enrichment - a significant time reduction from the current standard procedures (Kim et al., 2018). 


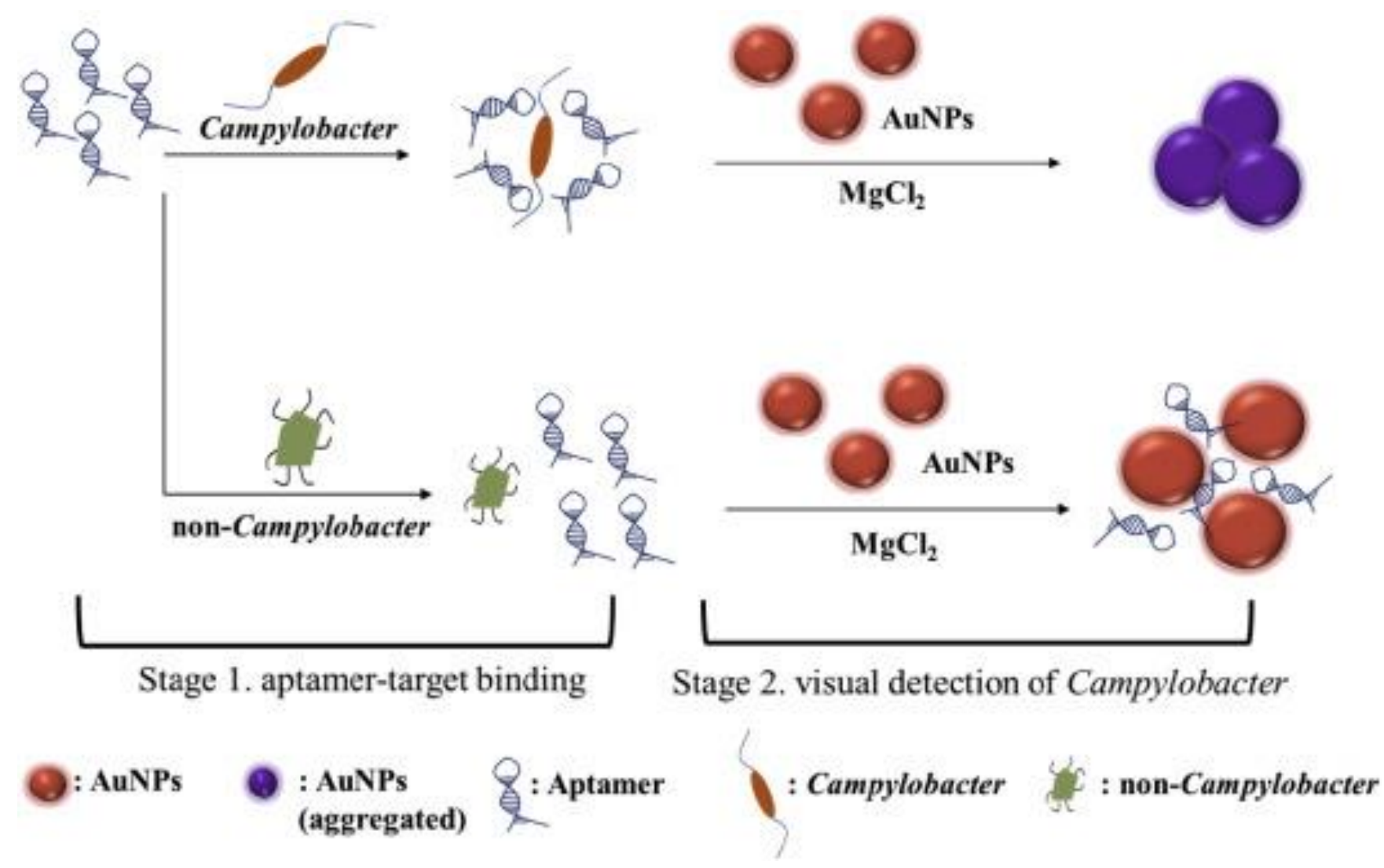

FIGURE 3 Schematic illustration of the principle of detection in the two-stage aptasensor platform developed by Y.-J. Kim et al (Kim et al., 2018). Reprinted with permission from Ref. (Kim et al., 2018). Copyright $\odot 2018$ Elsevier.

Du et al. (Du et al., 2018) have demonstrated the ability to detect Listeria monocytogenes using oligonucleotide-functionalized GNPs (OLG-GNPs) as a detection probe. This colorimetric assay requires bacterial DNA extraction and amplification of the hlyA gene from L. monocytogenes (corresponding to the OLG probe) via PCR prior to analysis. Upon addition of OLG-GNPs, the presence of either PCR product hlyA gene or target genomic DNA prevented aggregation of GNPs while negative samples led to aggregation and a colorless solution which was readily detected with the naked eye. The limit of detection was $48.4 \mathrm{ng}$ and $100.4 \mathrm{ng}$ respectively (Du et al., 2018).

Viable emetic Bacillus cereus was similarly visually detected in milk by $\mathrm{Li}$ et al. (Li et al., 2018) using an unmodified GNP assay developed with propidium monoazide (PMA)-asymmetric polymerase chain reaction (as PCR). In this assay, the PMA serves to eliminate false positives given by non-viable bacteria present in tested samples as it prevents amplification of PMA-intercalated DNA. In the presence of amplified target ssDNA (positive samples), the GNP assay remained ruby red as they were protected by aggregation, however in the absence of target ssDNA (negative samples) a striking visual color change to blue-purple occurred rapidly with aggregation. The color 
change was found to be directly linked to the concentration of B. cereus in the samples and the absorbance ratio A650nm/A520nm as measured by ultraviolet-visible (UV-vis) spectroscopy was found to be directly proportional to the concentration of the pathogen (Li et al., 2018).

While most GNP colorimetric assays require sample enrichment prior to analysis, Thiramanas and Laocharoensuk (Thiramanas \& Laocharoensuk, 2016) have taken advantage of the strong electrostatic interactions of positively charged polyethyleneimine-coated GNPs (PEI-GNPs), negatively charged enzymes ( $\beta$-galactosidase), and bacteria to create a competitive binding assay to eliminate this step. Binding of the PEI-GNPs to the enzymes inhibits their activity, however in the presence of large quantities of bacteria the PEI-GNPs will preferentially bind to the LPS of gram negative bacteria (such as enterotoxigenic $E$. coli) or the teichoic acids of gram positive bacteria ( $S$. aureus) and enzymatic activity will be restored. The enzymatic activity can then be colorimetrically monitored through hydrolysis of substrate chlorophenol red $\beta$-D-galactopyranoside, causing an evident yellow to red color change which could be detected within 10 min using a UV-vis spectrophotometer or by eye in 2-3 h. This assay was successfully applied to drinking water samples for the detection of both gram positive and gram negative bacteria with a limit of detection of $10 \mathrm{CFU}$ $\mathrm{mL}^{-1}$ (Thiramanas \& Laocharoensuk, 2016).

\subsection{Lateral flow assay}

Lateral flow assays (LFAs) are a type of immunochromatographic technique that has been widely used to detect target analytes in sample matrices. These assays are easy, rapid, and there is no need to use expensive or complicated equipment for detection the signal. Furthermore, the assay is highly portable. The earliest development of this technique did not use GNPs, but the later inclusion of GNPs increased the sensitivity of detection of target analytes.

Similar to solution-based colorimetric assays, many types of molecules can be conjugated onto the surface of the GNPs. The common molecules used for foodborne pathogenic detections are antibodies or nucleic acid sequences. The situation for the Enterobacteriaceae (Salmonell spp., E. coli) have been reviewed by Singh et al. (Singh, Sharma, \& Nara, 2015) who find that, in general the limit of detection is about $1 \times 10^{5} \mathrm{CFU} \mathrm{mL}^{-1}$ without enrichment, down to about $1 \mathrm{CFU} \mathrm{mL} \mathrm{m}^{-1}$ after enrichment.

As one example, Liu et al. (Liu et al., 2013) prepared nucleic acid-based LFAs by conjugating $16 \mathrm{~S}$ rDNA/rRNA to GNPs for detection Salmonella in food. The detection probe was prepared by modifying a thiol group on oligonucleotide (DNA sequence tagged with 10 adenosine residues and thiols). The target analyte (Salmonella) was hybridized with a capture probe and then a detection probe. The membrane was dipped into this hybridized analyte in combination with silver enhancement at the test membrane. The sample that contained Salmonella could be detected at the detect line at $10^{4} \mathrm{CFU} \mathrm{mL} \mathrm{m}^{-1}$ and produced a color on the membrane. 
Although the use of nucleic acid sequences as a molecular ligand to target pathogens is sensitive, it is important to note here that, to prepare the sequence of the nucleic acid, the PCR technique is usually needed. Unfortunately, use of PCR imposes specific requirements such as expensive reagents, special equipment, and the availability of highly skilled technicians. This has stimulated interest in another recent version of nucleic acid sequence preparation that can be done by isothermal amplification of nucleic acid sequences (Niessen, Luo, Denschlag, \& Vogel, 2013). This type of amplification does not need any thermal cycling equipment and only a constant temperature is applied to amplify nucleic acid sequences. GNPs can be included to provide for a strong color change. There are several types of isothermal amplification. For example, loop-mediated amplification (LAMP) is commonly used in combination with GNP-based LFAs. Unfortunately, LAMP is susceptible to contamination and this will cause inaccurate results. In 2017, Zhao et al (Zhao et al., 2017) demonstrated how to solve this problem by adding propidium monoazide (PMA). In their technique they used $30 \mathrm{~nm}$ GNPs and LFA together, and they could detect Salmonella in artificially contaminated powder infant formula at the detection limit of $2.2 \mathrm{CFU} \mathrm{\textrm {g } ^ { - 1 }}$ without doing any enrichment process. Their sensitivity was actually higher than using conventional PCR technique to detect Salmonella. On the other hand, LAMP requires a complicated priming condition. In contrast, another isothermal amplification technique called helicase-dependent amplification (HAD) does not (Du, Zhou, Li, \& Wang, 2017). The use of thermophilic HAD to amplify target nucleic acid (invA gene) for Salmonella detection was demonstrated by Du et al. (Figure 4) (Du, Zhou, Li, \& Wang, 2017). This technique could detect 1.3-1.9 CFU g ${ }^{-1}$ or CFU mL ${ }^{-1}$ of Salmonella contaminated in food (chicken products and cereal) after $2 \mathrm{~h}$ enrichment. But, it needed another $2 \mathrm{~h}$ of enrichment for Salmonella contaminated in milk. This indicates that the nature of contaminated food has an impact on the time required for the detection assay.
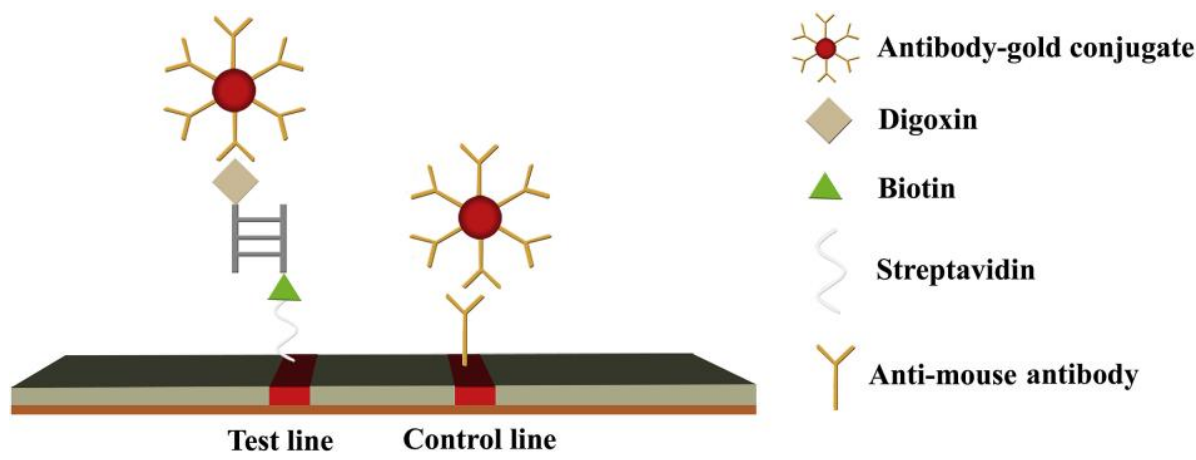

FIGURE 4 A schematic depiction of the principle of GNP-based LFA to target genomic DNA (invA gene) amplified by thermophilic HAD for Salmonella detection. The invA gene is labeled with digoxin and biotin (Du, Zhou, Li, \& Wang, 2017). Reprinted with permission from Ref. (Du, Zhou, Li, \& Wang, 2017). Copyright@2017 Elsevier. 
Although the use of nucleic acid as a specific target can provide a high sensitivity, it requires complicated protocols and sophisticated equipment to prepare nucleic acid molecules as discussed previously. The use of proteins as a target molecule can help decrease these problems. Suria et al. (Suria, Afendy, Azlina, \& Zamri, 2015) developed a LFA to detect E. coli O157:H7 by physically conjugating $40 \mathrm{~nm}$ GNPs with polyclonal antibody (IgG) against E. coli O157:H7. The conjugate (GNP-PolyIgG) was sprayed on a LFA strip. If the test sample contains E. coli O157:H7, then binding between E. coli O157:H7 and GNP-PolyIgG conjugates will occur, resulting in forming of the GNP color on the strip. There was a high specificity to only their target; E. coli O157:H7 (Figure 5). However, as with the other techniques discussed previously, the detection of the foodborne pathogens still required that the bacterial content be enriched in the sample prior to analysis being attempted.

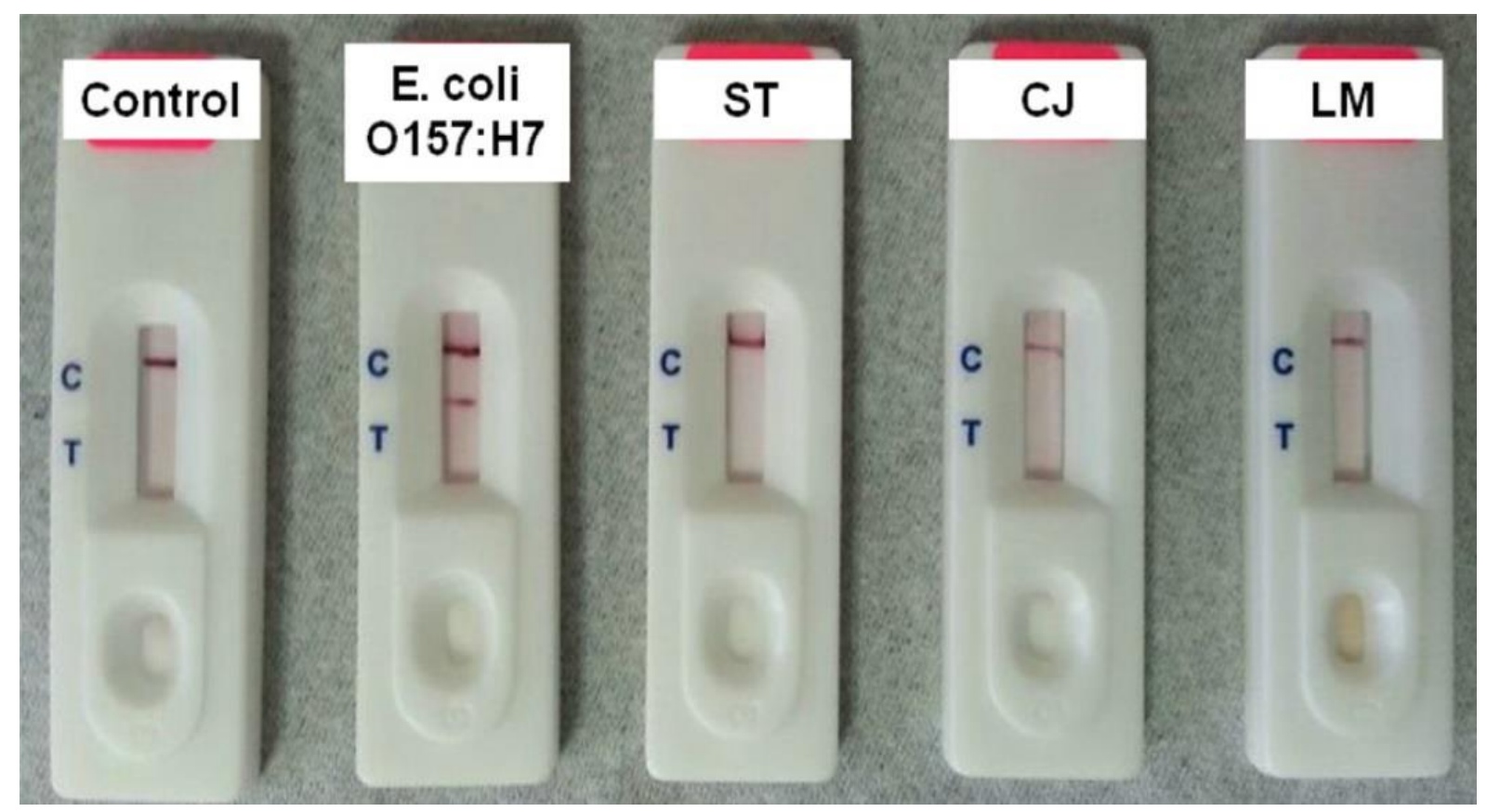

FIGURE 5 The detection of $E$. coli $\mathrm{O} 157: \mathrm{H} 7$ by using GNPs-based LFAs. The strip only detects $E$. coli $\mathrm{O} 157: \mathrm{H} 7$ and produces the red color of GNPs at the control line (C) and the test line (T). In the case of Salmonella typhimurium (ST), Campylobacter jejuni (CJ), and Listeria monocytogenes (LM), the red color cannot be detected at the test line. Reprinted with permission from Ref. (Suria, Afendy,Azlina, \& Zamri, 2015). Copyright@2015 Universiti Putra Malaysia.

Immunomagnetic beads offer a possible solution in this regard. For example, Cui et al. (Cui et al., 2013) combined magnetic beads with the GNP-based LFA for the detection of E. coli 0157:H7. They used magnetic beads of $\sim 180 \mathrm{~nm}$ diameter to which the antibody against E. coli $0157: \mathrm{H} 7$ had been attached. This was used to separate and concentrate the target bacteria before testing samples on a GNP-based LFA (Figure 6). This technique only needed $6 \mathrm{~h}$ enrichment time and a few more minutes for E. coli $0157: \mathrm{H} 7$ detection in food inoculated with only $10 \mathrm{CFU} \mathrm{g}^{-1}$ E. coli $0157: \mathrm{H} 7$. The total 
time was $\sim 72$ min without any use of sophisticated skills or equipment, and the combination of immunomagnetic separation and GNP-based LFA produced a higher sensitivity than that possible without the immunomagnetic separation.

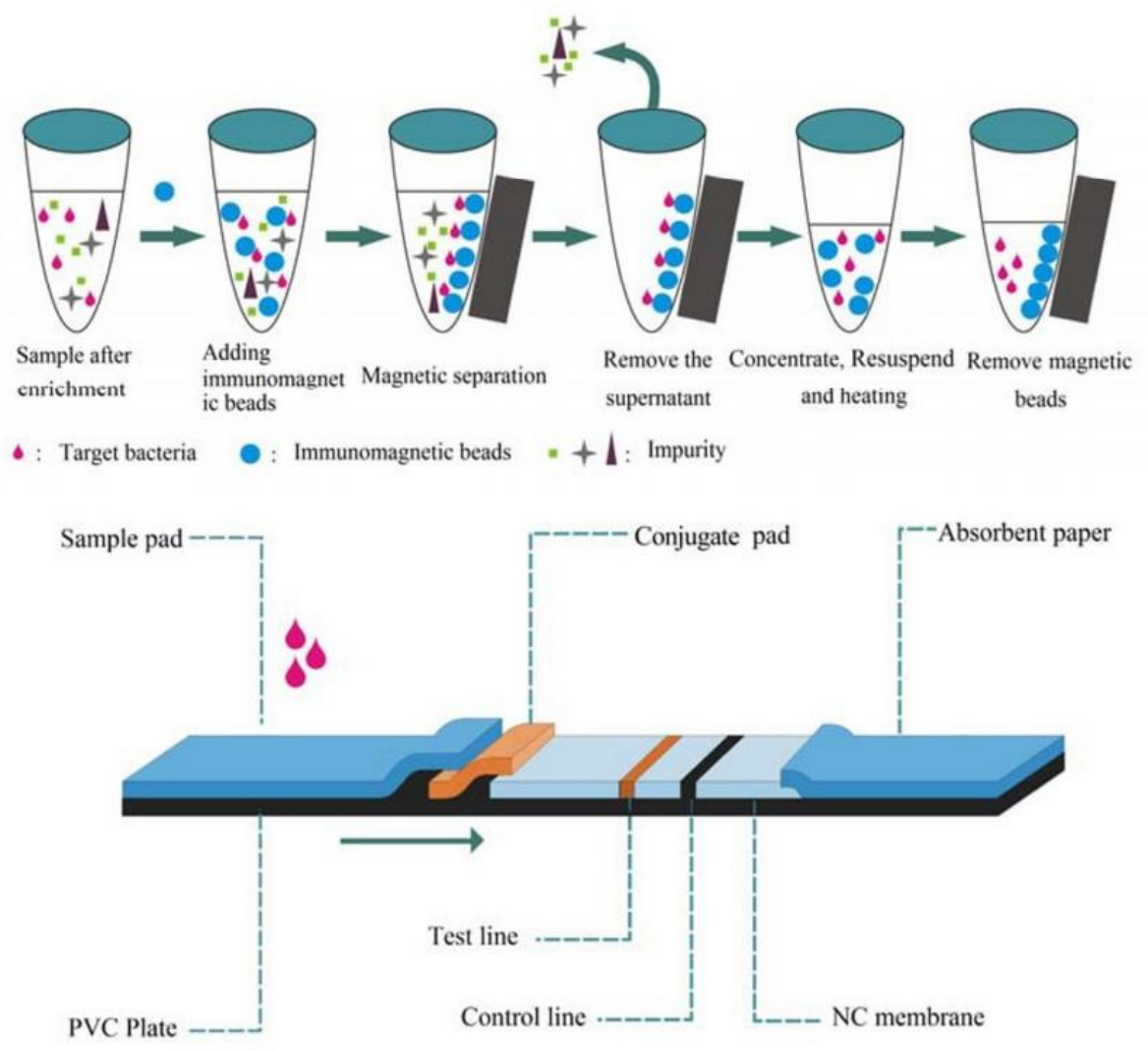

FIGURE 6 Schematic illustration of process to concentrate and detect E. coli 0157:H7 using immunomagnetic beads. (Top) Separation and concertation of target bacteria. (Bottom) GNP-based LFA for E. coli 0157:H7 detection. Reprinted with permission from Ref. (Cui et al., 2013). Copyright@2013 Elsevier.

\subsection{Refractometric sensors}

The frequency of an LPSR is red-shifted by an increase in the dielectric function of the surrounding environment. This shift can be detected using a spectrometer and has been the inspiration for a large number of 'refractometric' sensing schemes based either on propagating surface plasmon polaritons (Homola, 2008), or on localized surface plasmon resonances on discrete nanoparticles (Yoo \& Lee, 2016). There has not been much uptake of these ideas for detecting food pathogens however.

In some sensor designs the capture of a bacterium onto the surface of a nanoparticle has been correlated with an increase in absorptance rather than a shift in the peak. For example, Oh et al. (Oh et al., 2017) have shown how this phenomenon can be used to make a sensor for rapid detection of $S$. typhimurium: first, a portable LSPR sensing ship was conjugated with aptamer and GNPs, next the sensor was incubated for $30 \mathrm{~min}$ within a sample containing S. typhimurium, finally the intensity of the LSPR peak was measured by a UV/Vis spectrophotometer (the wavelength of the measurement 
was not given) (Figure 7). The presence of the bacterium is deduced from the increase in absorbance at the unspecified wavelength. The detection limit was reported to be $1 \times 10^{4} \mathrm{CFU} \mathrm{mL}^{-1}$.

(a)

(b)

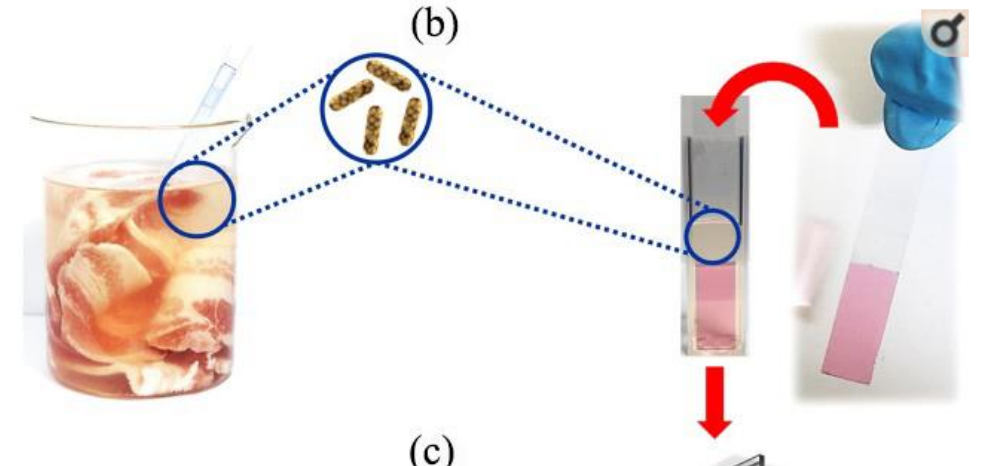

(d)

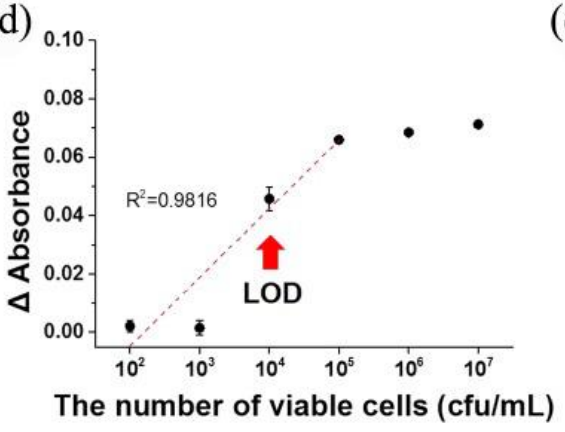

(c)

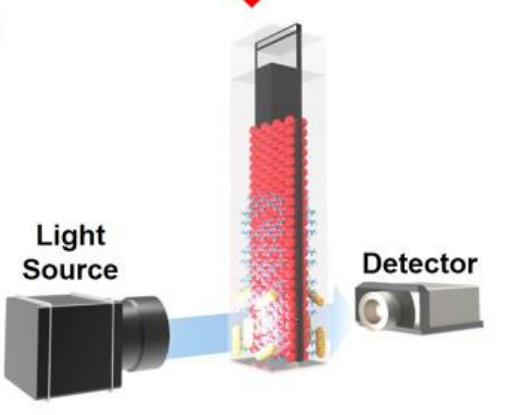

FIGURE 7 Schematic overview of Salmonella typhimurium detection in samples using a GNPaptamer-based LSPR sensing chip with the property that absorbance is correlated with number of attached live bacteria. Reprinted with permission from Ref. (Oh et al., 2017). Copyright@2017 Nature.

\subsection{SERS}

Surface enhanced Raman scattering (SERS) refers to the massive amplification $\left(1 \times 10^{5}\right.$ and more) of a Raman signal that is obtained by using noble metal substrates (Albrecht \& Creighton, 1977). There have been many applications of this discovery in the life sciences. One of the present authors has, for example, used colloids of Au nanorods to detect very small amounts of biological molecules on the surfaces of macrophage cells (Pissuwan \& Hattori, 2016), or to detect different molecules that are actually inside cells (Pissuwan, Hobro, Pavillona, \& Smith, 2014). The latter mode of operation provides one of the very few techniques (Dowd, Pissuwan, \& Cortie, 2014) available for remote optical analysis of the intracellular chemical environment (Qian et al., 2008). Not surprisingly, SERS has also received attention as a tool for identifying pathogens, including in food (Zhao, Li, \& Xu, 2018). 
As a recent example of what is possible, a relatively complicated 'sandwich assay' for the detection of E. coli by SERS using GNPs (spherical shape) and gold nanorods (GNRs) was reported by Bozkurt et al. (Bozkurt et al., 2018). In that case, hydrolyzed SERS substrate (5-bromo-4-chloro3-indolyl phosphate; BCIP) generated by alkaline phosphatase (ALP) was used as a label for the SERS. The amount of ALP is directly related to the number of bacteria (Figure 8). Enrichment was achieved using gold-coated magnetic nanoparticles to which an E. coli antibody had been conjugated. Once separated, GNRs that had been coated with both ALP and an antibody against E. coli was added. This allowed for a highly selective interaction of ALP and the E.coli. Thereafter, the mixture of E. coli and nanoparticles was blended with the BCIP substrate, and the ALP on the surface of any attached GNRs could hydrolyze the BCIP and produce 5-bromo-4-chloro-3-indole (BCI). The method was very sensitive, with a limit of detection of the order of $10 \mathrm{CFU} \mathrm{mL} \mathrm{m}^{-1}$. References 19 to 23 of Bozkurt et al. (Bozkurt et al., 2018) provide additional examples of using SERS to detect E. coli.
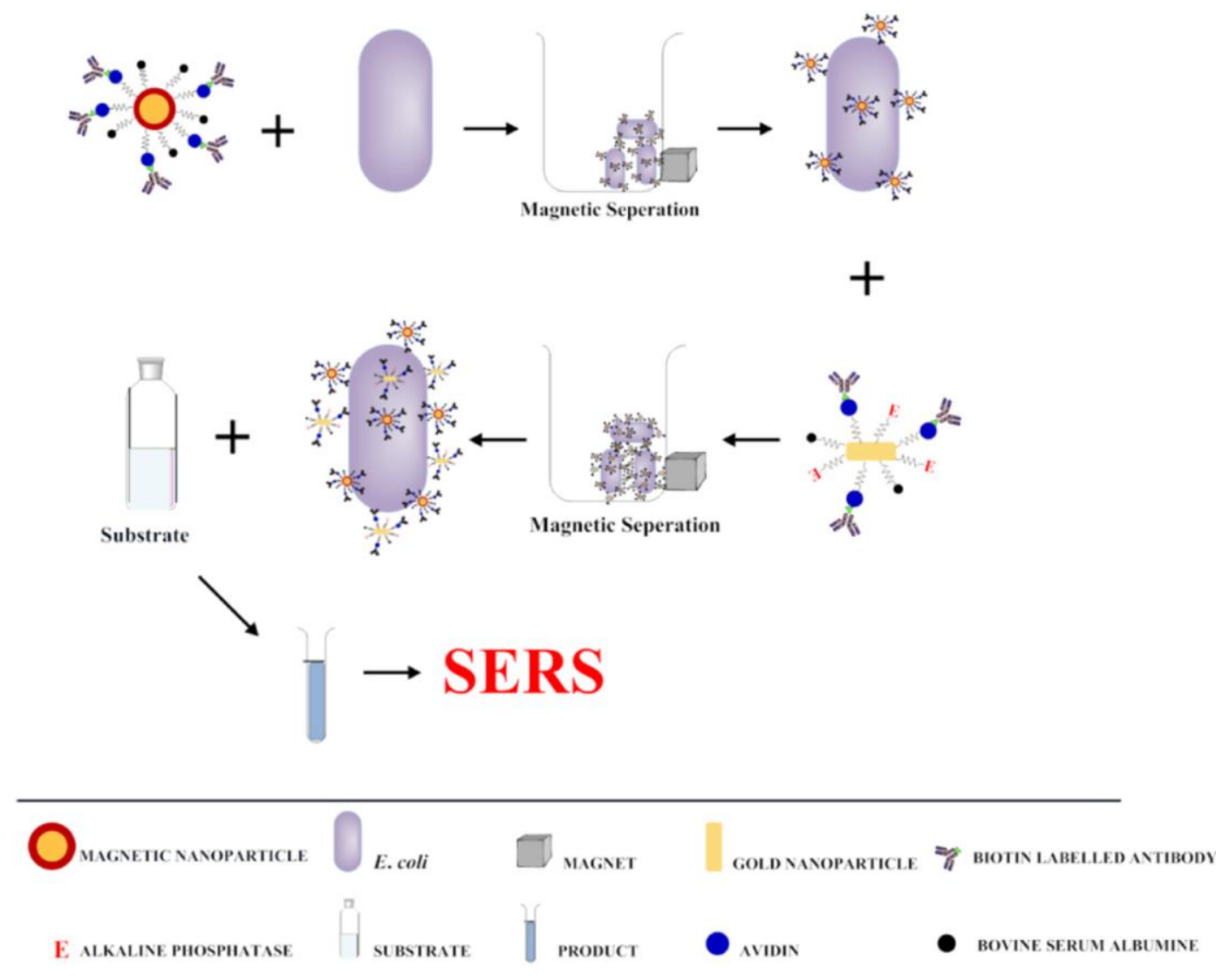

FIGURE 8 An overview of ALP labelled SERS active assay for Escherichia coli detection. Reprinted with permission from Ref. (Bozkurt et al., 2018). Copyright@2018 Elsevier.

Gao et al. (Gao, Pearson, \& He, 2018) used the properties of 4-mercaptophenylboronic acid (4MPBA) to construct a SERS sensor for bacteria. This compound can interact with the peptidoglycan that is a characteristic of bacterial cell walls and it has a strong and unique SERS signal. Samples are 
placed on a membrane and 4-MPBA was added. If any E. coli O157:H7 cells are present, they will react with the 4-MPBA. The SERS detection was performed after adding GNPs $(50 \mathrm{~nm})$ and the 4MPBA peak at $1072 \mathrm{~cm}^{-1}$ was used to indicate the presence of bacteria. SERS mapping of the samples (Figure 9) showed that E. coli O157:H7 could be detected down to about $10 \mathrm{CFU} \mathrm{mL}^{-1}$ and without any enrichment (Figure 9). However, this approach cannot distinguish between live or dead bacteria.

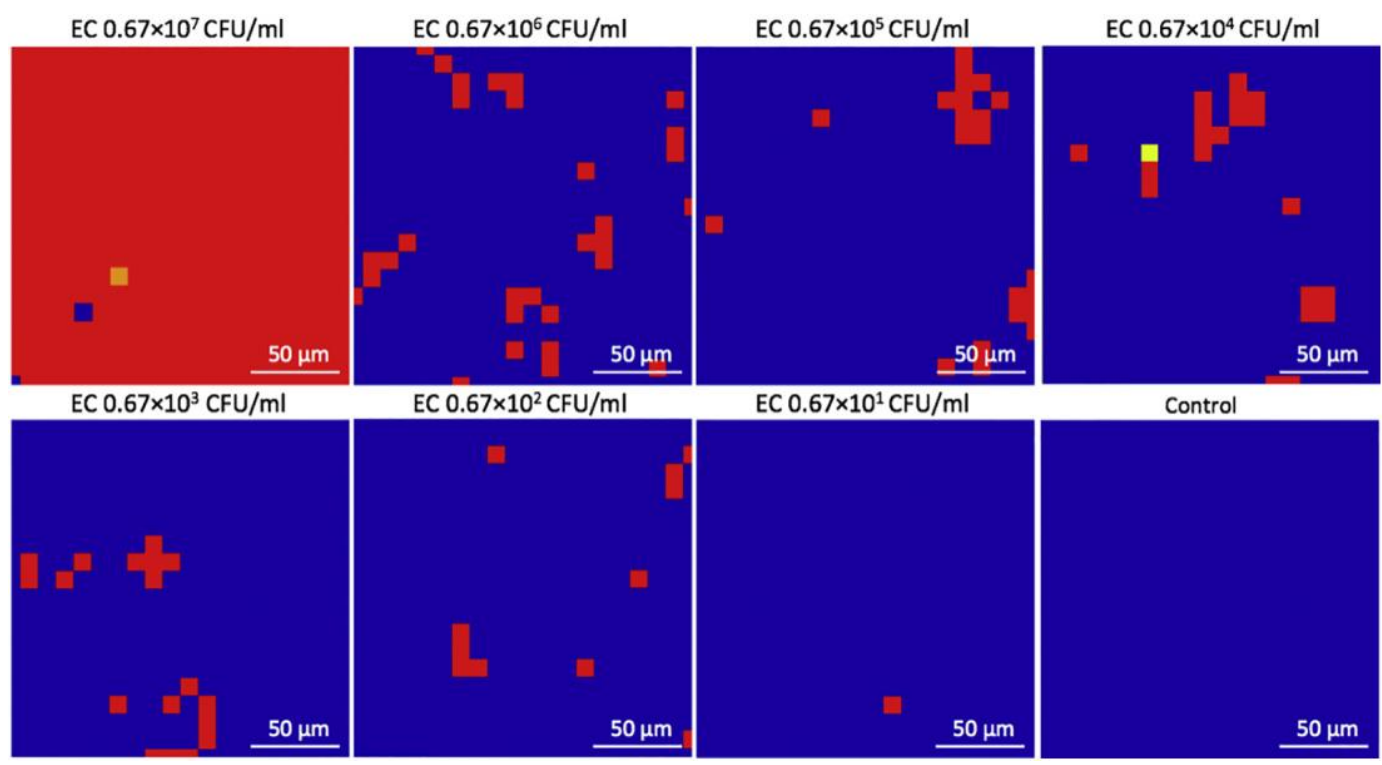

FIGURE 9 SERS maps of surface of sensor for different concentrations of E. coli O157:H7. Reprinted with permission from Ref. (Gao, Pearson, \& He, 2018). Copyright@2018 Elsevier.

Uusitalo et al. (Uusitalo et al., 2016) fabricated a polymer SERS substrate using a roll-to-roll technique. This was combined with immunomagnetic separation and GNPs to provide an easily upscalable platform for detection of Listeria innocua. A detection limit of about $1 \times 10^{4} \mathrm{CFU} \mathrm{mL}^{-1}$ was achieved.

The combination of GNPs and aptamers as a SERS nanoprobe has also been recently reported (Ma, Xu, Xia, \& Wang, 2018; Xu, Ma, Wang, \& Wang, 2018). So-called 'spiny' GNPs were modified with 4-mercaptobenzoic acid (4-MBA) and thiolated Salmonella typhimurium aptamer. The 4-MBA has a very distinctive Raman signal and is commonly used as a Raman reporter. The aptamer was used as a probe to detect $S$. typhimurium in pork meat (Figure 10) by monitoring the intensity of the 4-MBA SERS peak at $1586 \mathrm{~cm}^{-1}$. The results were correlated against the standard colony counting method. This technique can be used to detect $S$. typhimurium at the range of $10-10^{5} \mathrm{CFU} \mathrm{mL}{ }^{-1}$ with a limit of

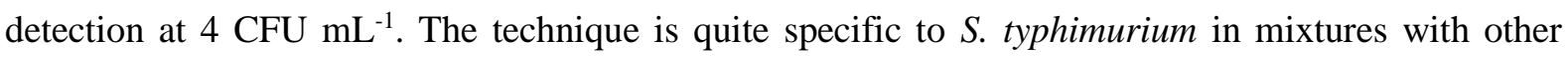
gram negative and gram positive bacteria (Ma, Xu, Xia, \& Wang, 2018). In a related example, the ssDNA1 aptamer (which is specific to $S$. typhimurium) was combined with a gold nanodimer constructed from $35 \mathrm{~nm}$ GNPs Then, $15 \mathrm{~nm}$ GNPs were conjugated with Cy3 labelled with ssDNA2. 
The Cy3 was used as a Raman reporter because it provides a strong SERS signal at $1203 \mathrm{~cm}^{-1}$. But, the limit of detection of these gold nanodimers to target $S$. typhimurium is less sensitive than using spiny GNPs (4 CFU mL $\left.{ }^{-1}\right)(\mathrm{Xu}$, Ma, Wang, \& Wang, 2018).

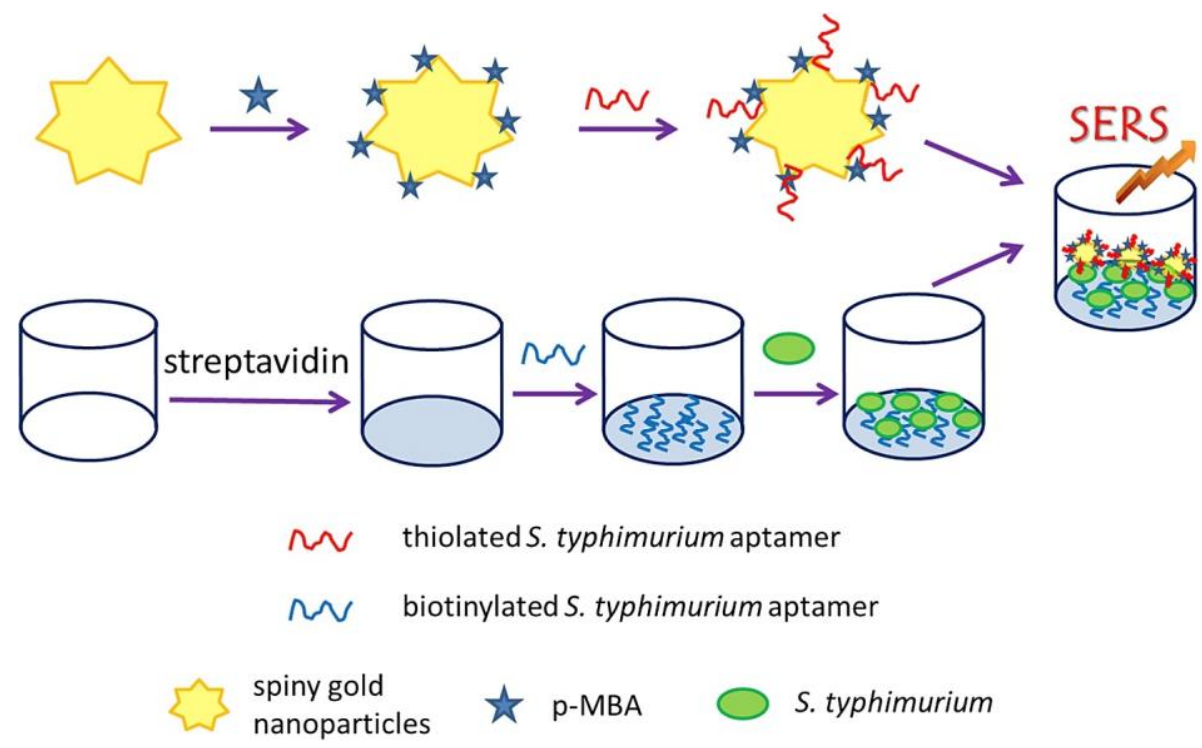

FIGURE 10 A schematic showing the use of spiny GNPs and aptamer as a SERS nanoprobe to detect Salmonella typhimurium. Reprinted with permission from Ref. (Ma, Xu, Xia, \& Wang, 2018). Copyright $\odot 2018$ Elsevier.

\subsection{Electrochemical techniques}

Electrochemical biosensing of pathogens using a GNP-platform is also feasible. For example, the incorporation of GNPs into an electrochemical biosensor for E. coli 0157:H7 was reported by Wang and Alocilija (Wang \& Alocilja, 2015). Two types of nanoparticles were used in their study. These two forms were 1) polymer-coated MNPs and 2) carbohydrate-coated GNPs. The target E. coli 0157:H7 was separated by polyaniline capped MNPs and then conjugated with anti-E. coli 0157:H7 monoclonal antibody via an electrostatic interaction. Similar to the work reported by Cui et al. (Cui et al., 2013), these conjugated MNPs work as a separator by separating target E. coli 0157:H7 from the sample matrix. The second particle; carbohydrate-coated GNPs, was conjugated to anti-E. coli 0157:H7 polyclonal antibody to having a role as a detector by generating electrochemical signals. After the complex of MNPs and GNPs attached to target E. coli 0157:H7 was magnetically separated out, the amount of E. coli $0157: \mathrm{H} 7$ was measured through an electrochemical signal using a potentiostat (Figure 11). The signal was in a linear relationship with the amount of E. coli 0157:H7. This technique could detect E. coli $0157: \mathrm{H} 7$ at concentrations of $10-10^{6} \mathrm{CFU} \mathrm{mL}^{-1}$. In related work by 
Alocilija et al, the attachment of bacteria to GNPs that are in turn bound to an RFID tag immersed in milk alters the electrochemical impedance of the surface which then alters the radio signal broadcast by the RFID tag.
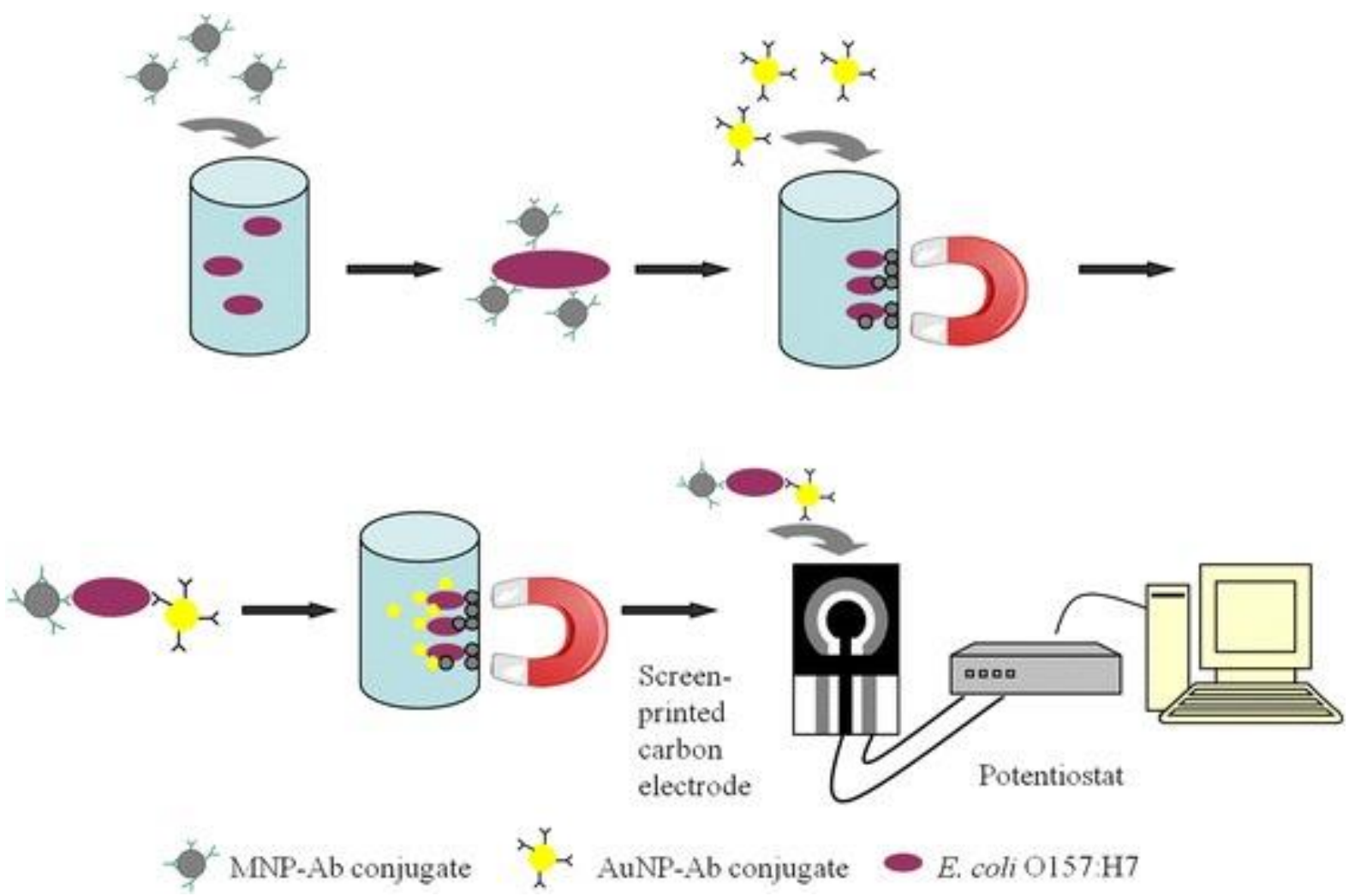

FIGURE 11 A schematic representation of the combination of polyaniline capped MNPs conjugated with anti-E. coli 0157:H7 monoclonal antibody to separate E. coli 0157:H7. The carbohydrate-coated GNPs conjugated anti-E. coli $0157: \mathrm{H} 7$ polyclonal antibody was applied to form a sandwich structure with MNPs and to enhance electrochemical signals. Reprinted with permission from Ref. (Wang \& Alocilja, 2015). Copyright@2015 BioMed Central.

\subsection{Quartz crystal microbalance}

Recently Haddada et al. (Haddada, Salmain, \& Boujday, 2018) demonstrated the use of GNPs to enhance piezoelectric immunosensing of staphylococcal enterotoxin A (SEA; molecular weight $\sim 28$ $\mathrm{kDa}$ ). This toxin is commonly the cause of illness in food poisoning outbreaks (Loir, Baron, \& Gautier, 2003) and, therefore, detection of it at an early stage can also help limit spread of the problem. In the study of Haddada et al., they modified the surface of gold-and silicon-coated quartz crystal substrate with GNPs (with two diameters at $~ 13 \mathrm{~nm}$ and $40 \mathrm{~nm}$ ). The role of the GNPs here is to increase the active surface area of the sensor. As shown in Fig. 12, GNPs were applied on the gold or silicon substrate. Thereafter, GNPs on the substrate were treated with cysteamine (CEA) and 1,4phenylenediisothiocyanate (PDITC) to generate an amine reactive function that is suitable for 
covalently binding of Protein A on the GNPs surface. Then, the polyclonal rabbit anti-SEA antibody that is specific to SEA was immobilized on the Protein A. The functionalized sensor was then used as

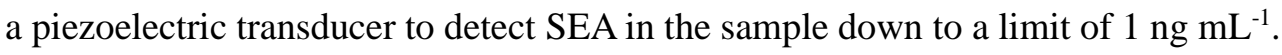

(a)

a)

(b)
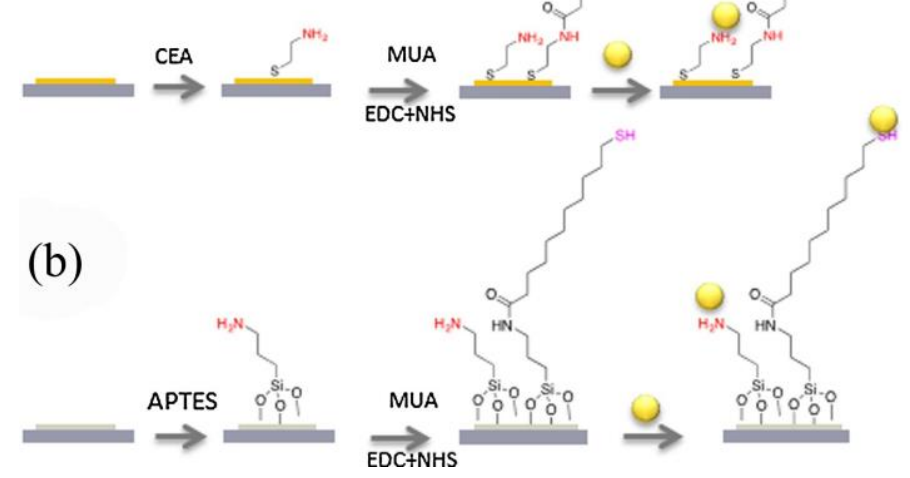

(c)

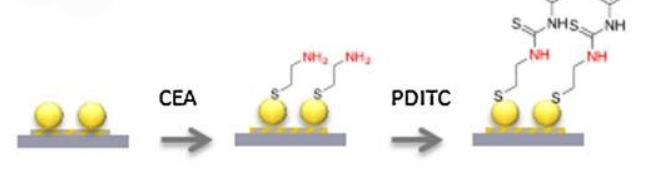

FIGURE 12 The surface modification of (a) gold and (b) silicon substrates by using GNPs. (c) The treatment of GNPs by with cysteamine (CEA) and 1,4-phenylenediisothiocyanate (PDITC). Reprinted with permission from Ref. (Haddada, Salmain, \& Boujday, 2018). Copyright@2018 Elsevier.

\subsection{Comparison of test methods}

The great diversity of techniques available to detect single types of pathogen makes it difficult to confidently predict the future development of this field. Essentially, the available techniques can be divided into rapid or slow, expensive or cheap, field- or laboratory-based, sensitive or approximate, amongst other considerations, and no single method is ideal for all scenarios. The colorimetric and lateral flow techniques are certainly fast to apply (but may require a lengthy pre-enrichment step) and do not require skilled manpower or sophisticated equipment. The refractometric, SERS, electrochemical, and quartz microbalance methods require specialized equipment, although this can be relatively inexpensive in the case of the refractometric and electrochemical sensors. Colorimetric and lateral flow techniques can be readily deployed in the field, but the others may require a laboratory environment for best results. We expect that individual food processing industries will in many cases adopt specific variations of the technologies described above, and that no single method will dominate.

\section{MULTIPLE DETECTION OF FOODBORNE PATHOGENS}

The techniques described above are suitable for detection of a single, pre-identified species of pathogen. A complicating issue is that there may be more than one species of pathogen in the food 
sample. Some solutions to this latter problem have been demonstrated. For example, Li et al. (Li et al., 2011) fabricated an immunochromatographic LFA to be used as an immune-disc sensor for detection of a mixture of Pseudomonas aeruginosa and Staphylococcus aureus. Their assay had an ability to distinguish the type of bacteria in the mixture. They conjugated $20 \mathrm{~nm}$ GNPs to polyclonal antibodies against the target bacteria, and monoclonal antibodies against the same bacteria were immobilized on an arm of a 'peace design' the LFA, Figure 6. The control line was immobilized polyclonal donkey anti Rabbit IgG. The samples containing only $S$. aureus (Figure 13a) or only P. aeruginosa (Figure $13 \mathrm{~b}$ ) and the mixture of $S$. aureus and $P$. aeruginosa (Figure 13c) could be clearly distinguished. This technique provided promising results for detecting target bacteria in samples that have more than

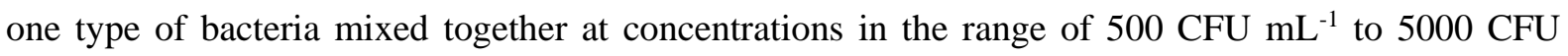
$\mathrm{mL}^{-1}$. No pre-treatment of the samples was required (Li et al., 2011). Further work is still probably required, however, to confirm whether false positive/negative results may be obtained by using this technique.

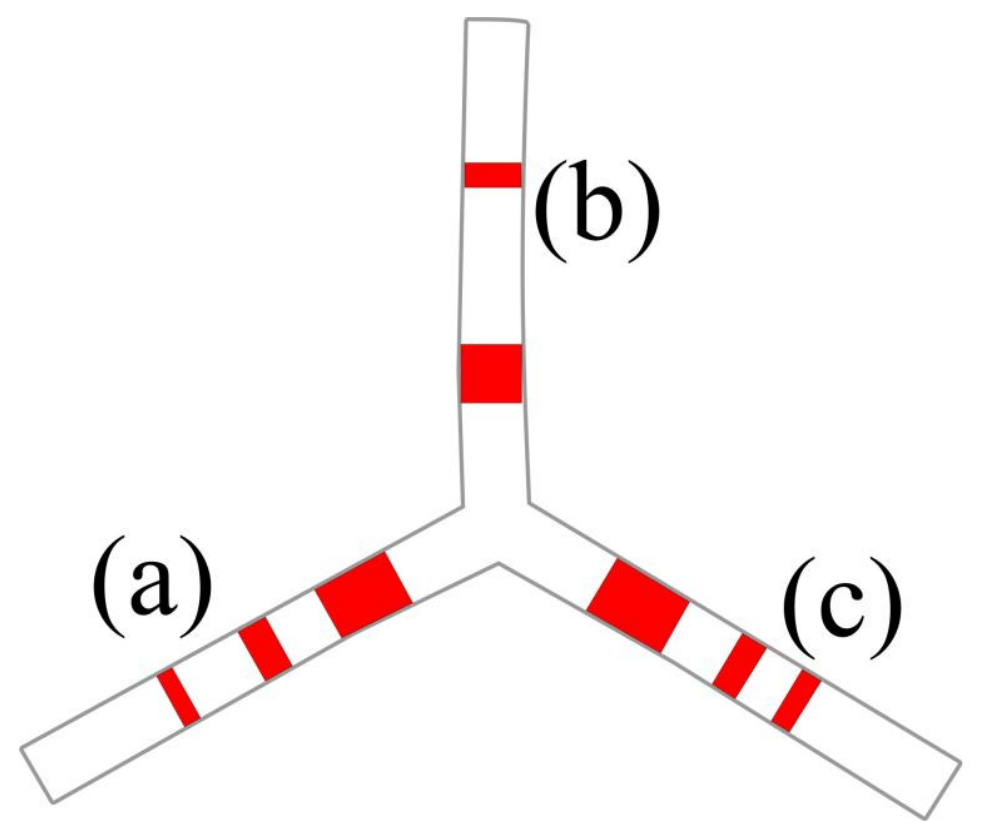

FIGURE 13 The 'peace design' GNP-based-LFA format was used to distinguish target bacteria; Staphylococcus aureus in the mixed bacteria (S. aureus \& P. aeruginosa). (a) The sample contains only $S$. aureus, (b) The sample contains only P. aeruginosa and (c) the mixture of $S$. aureus and $P$. aeruginosa, were tested on GNPs-based Peace design LFA (Li et al., 2011).

A class of techniques designated 'high throughput methods' has become attractive recently. These techniques can detect multiple strains/species of pathogens at one time. Implementations such as microarrays (Li, 2016), multiplex PCR (Rodríguez et al., 2015), and genome scale metabolic technique (Metz, Ding, \& Baumler, 2018) have been developed. However, these techniques require 
sophisticated analytical equipment and are not well suited for routine or field detection. Similar to previous discussion in single detection section, an easy onsite assay is necessary to detect foodborne pathogens. One solution is to extend the design of GNP-based immunochromatographic strips or LFAs to detection of multiple species of foodborne pathogen but this is quite challenging.

In 2016, a simultaneous detection of Shigella boydii and E. coli O175:H7 using gold immunochromatographic strip was demonstrated by Song et al. (Song et al., 2016). GNPs with a diameter of $\sim 15 \mathrm{~nm}$ were conjugated with monoclonal antibodies against these two bacteria through ionic and hydrophobic interactions between GNPs and antibodies at the conjugated $\mathrm{pH}$ around the isoelectric point of antibodies. The monoclonal antibodies against $S$. boydii and E. coli O175:H7 were used for conjugating with GNPs. A mixture of GNP-antibody conjugates specific to $S$. boydii and $E$. coli $\mathrm{O} 175: \mathrm{H} 7$ was prepared. As usual, the LFA needs a conjugate pad that contains GNP-antibody (or other ligands) conjugates in its system. When the capture antibody of each bacteria was immobilized on the membrane, it could detect whether S. boydii or E. coli $\mathrm{O} 175: \mathrm{H} 7$ or both bacteria were contained in the sample or not. The preparation of the membrane for GNPs-based LFA is shown in Fig. 14a-e. This technique could detect $S$. boydii or E. coli $\mathrm{O} 175: \mathrm{H} 7$ at a concentration of $10^{6} \mathrm{CFU}$ $\mathrm{mL}^{-1}$ (Figure 15). The pre-incubation time of target bacteria contaminated in food was differently depending on the type of food. In their case, it took $10 \mathrm{~h}$ for bread and milk and $8 \mathrm{~h}$ for jelly. This is also another example to show that the type of food impacts on the analysis time. Their detection

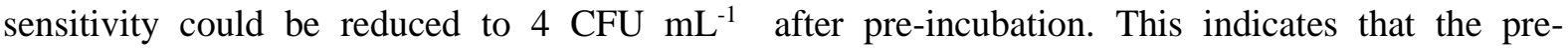
incubation could also help increase the detection sensitivity.

FIGURE 14 The schematics represent GNP-based LFA for detection Escherichia coli O157:H7 and Salmonella boydii at one time. Reprinted with permission from Ref. (Song et al., 2016). Copyright@2016 Elsevier.

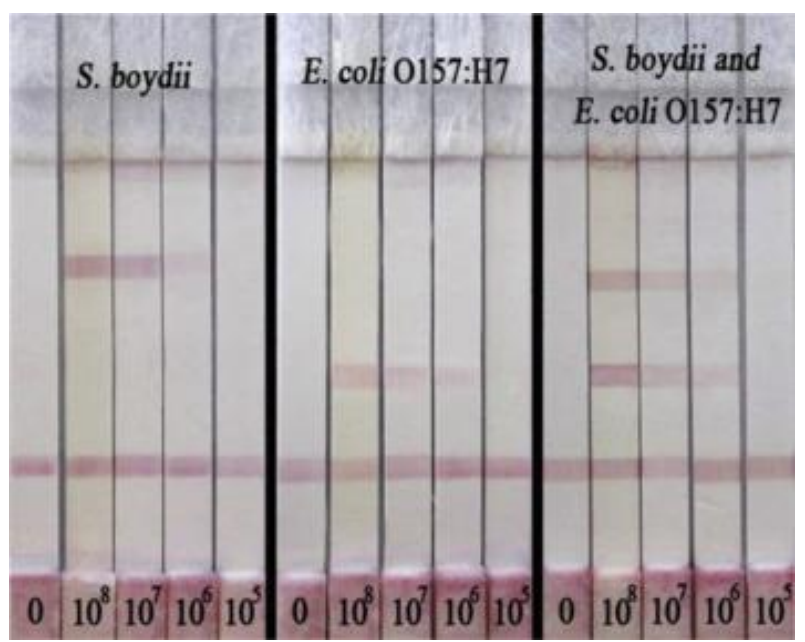


FIGURE 15 The red colors present on the strip after testing with the samples containing Salmonella boydii, Escherichia coli $\mathrm{O} 157: \mathrm{H7}$, and the mixture of S. boydii and E. coli O157:H7. Reprinted with permission from Ref. (Song et al., 2016). Copyright@2016 Elsevier.

In 2017, Wang et al. (Wang et al, 2017) established GNP-based LFAs ( 15 nm GNPs) for multiple detection of twelve Listeria spp. With their technique, they could detect broadly cross-

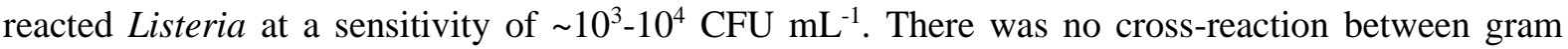
negative and gram positive bacterial strains. Spiked milk samples inoculated with 1-9 CFU $\mathrm{mL}^{-1}$ Listeria were enriched for a further $8 \mathrm{~h}$. It is well known that P60 protein is expressed on the surface of Listeria. Therefore, the authors produced monoclonal antibody against the P60 protein to detect this target protein. Then, the samples were applied to their designed GNP-based LFAs that had monoclonal antibody of P60 (Listeria spp. specific protein). Eight strains of Listeria monocytogenes and four strains of Listeria spp. could be detected by using their technique. This can be further developed to build an effective multiple detection platform of many foodborne pathogens. It will be obvious from the many examples provided above that the limit of detection varies radically between techniques. The situation is summarized in Table 2.

Testing simultaneously for multiple pathogens is obviously a very challenging scenario, yet if it can be done cost-effectively and efficiently there could be significant benefits to society. Unfortunately, however, given the enormous number of potential pathogens, it is an open question whether any test that is only developed for two or three specific pathogens can ever be widely applicable in the marketplace. 
TABLE 2 The limit of detection for foodborne bacteria, for different techniques.

\begin{tabular}{|c|c|c|c|}
\hline $\begin{array}{l}\text { Detection } \\
\text { techniques }\end{array}$ & Foodborne pathogens & $\begin{array}{l}\text { Limit of detection } \\
\qquad\left(\mathrm{CFU} \mathrm{mL}^{-1}\right)\end{array}$ & Enrichment time \\
\hline $\begin{array}{l}\text { Refractometric } \\
\text { sensors } \\
\text {-Aptamer (Oh et al, } \\
\text { 2017) }\end{array}$ & $\begin{array}{l}\text {-Salmonella } \\
\text { typhimurium }\end{array}$ & $10^{4}$ & \\
\hline $\begin{array}{l}\text { SERS } \\
\text {-BCIP substrate, } \\
\text { magnetic separation, } \\
\text { ALP/target antibody } \\
\text { (Bozkurt et al, 2018) } \\
\text {-Raman reporter (4- } \\
\text { MBA) (Gao, Pearson, } \\
\text { \& He, 2018) } \\
\text {-A roll-to-roll } \\
\text { technique } \\
\text { Immunomagnetic } \\
\text { separation (Uusitalo et } \\
\text { al, 2016) } \\
\text {-spiny } \\
\text { apatamer, 4-MBA } \\
\text { (Ma, Xu, Xia, \& } \\
\text { Wang, 2018) }\end{array}$ & $\begin{array}{l}\text {-E. coli 0157:H7 } \\
\text {-Listeria innocua }\end{array}$ & $\begin{array}{l}10 \\
10^{4}\end{array}$ & Without enrichment \\
\hline $\begin{array}{l}\text { Electrochemical } \\
\text { Techniques } \\
\text {-Carbohydrate-coated } \\
\text { GNPs, anti-E. coli } \\
\text { 0157:H7 polyclonal } \\
\text { antibody, MNPs } \\
\text { separation (Wang \& } \\
\text { Alocilja, 2015). }\end{array}$ & -E. coli $0157: \mathrm{H} 7$ & 10 & \\
\hline
\end{tabular}




\section{CONCLUSIONS AND FUTURE PERSPECTIVES}

New rapid-assay techniques based on gold nanoparticles offer a potential improvement on conventional techniques for the detection of pathogens in food. In principle the new technologies can provide a shorter analysis time, higher sensitivity, better selectivity, easier operation, and the capability to detect multiple pathogen types simultaneously. This review has shown that the detection of single types of pathogens using gold nanoparticles is very promising and appears ready for wider deployment.

There are, however, some issues that are holding back more wide-spread deployment of the GNP technology platform in the food industry. An important issue is the complicating influence of background microorganisms present in food, food matrices, food ingredients, and the physical food handling environment. Another concern is that techniques for the simultaneous detection of multiple pathogens need more development. Therefore, before these simple detection tools can be launched into the market, careful pilot testing and validation is needed to avoid any unexpected false negative or positive results.

Although a number of exciting technologies have been described above, it remains the case that there is no single 'ideal' solution to the problem of detecting pathogens in food. Broadly speaking the currently available methods suffer at one of the following disadvantages:

- there is a delay while a culture is produced, and/or

- the content of bacteria in the sample must first be enriched by some means, and/or

- the method of detection is specific to one or two species of pathogen only, and/or

- the methods require sophisticated equipment and personnel.

Overall, however, the rapid progress of diagnostic tools based on gold nanoparticles suggests that they will soon make an important niche contribution to controlling foodborne diseases.

\section{ACKNOWLEDGMENTS}

The authors acknowledge School of Mathematical and Physical Sciences, University of Technology Sydney and Faculty of Science, Mahidol University for supporting this work. The authors also thank Dr. Sujin Jiracheewanun for technical support.

\section{CONFLICT OF INTEREST}

The authors have declared no conflict of interest for this article. 
$\underline{\text { Biomedical applications of multifunctional plasmonic nanoparticles }}$

\section{REFERENCES}

Albrecht, M.G., \& Creighton, J. A.(1977). Anomalously intense Raman spectra of pyridine at a silver electrode. Journal of the American Chemical Society, 99, 5215 - 5217.

Algaba, I. G., Verhaegen, B., Jennes, M., Rahman, M., Coucke, W., Cox, E., Dorny, P., Dierick, K., \& Craeye, S. D. (2018). Pork as a source of transmission of Toxoplasma gondii to humans: a parasite burden study in pig tissues after infection with different strains of Toxoplasma gondii as a function of time and different parasite stages. International Journal for Parasitology, 48, 555-560.

Amendola, V., Pilot, R., Frasconi, M., Marago, O. M., \& Iati, M. A. (2017). Surface plasmon resonance in gold nanoparticles: A review. Journal of Physics: Condensed Matter, 29, 203002.

Binh, D. X., Minh, N. N., \& Nguyet, D. T. (2017). Prevalence of Listeria monocytogenes, E. coli, Salmonella Spp. and Staphylococcus aureus bacteria contamination on meat at public market in the North of Vietnam. SOJ Microbiology and Infectious Diseases, 5, 1 22.

Boyce, T. G., Mintz, E. D., Greene, K. D., Wells, J. G., Hockin, J. C., Morgan, D., \& Tauxe, R.V. (1995). Vibrio cholerae 0139 Bengal infections among tourists to southeast asia: an intercontinental foodborne outbreak. Journal of Infectious Diseases, 172, 1401-1404.

Bozkurt, A. G., Buyukgoz, G. G., Soforoglu, M., Tamer, U., Suludere, Z., \& Boyaci, I. H. (2018). Alkaline phosphatase labeled SERS active sandwich immunoassay for detection of Escherichia coli. Spectrochim Acta A: Molecular and Biomolecular Spectroscopy, 194, 8-13.

Brynestad, S., \& Granum, P. E. (2002). Clostridium perfringens and foodborne infections. International Journal of Food Microbiolog, 74, 195-202.

Bui, M. P. N., Ahmed, S., \& Abbas, A. (2015). Single-digit pathogen and attomolar detection with the naked eye using liposome-amplified plasmonic immunoassay. Nano letters, 15, 6239-6246.

Cacciò, S. M., Chalmers, R. M., Dorny, P., \& Robertson, L. J. (2018). Foodborne parasites: Outbreaks and outbreak investigations. a meeting report from the European network for foodborne parasites (Euro-FBP). Food Waterborne Parasitology, 10, 1-5.

Carnovale, C., Bryant, G., Shukla, R., \& Bansal, V. (2016). Size, shape and surface chemistry of nano-gold dictate its cellular interactions, uptake and toxicity. Progress in Materials Science, 83, 152-190.

Cho, I. H., \& Ku, S. (2017). Current technical approaches for the early detection of foodborne pathogens: challenges and opportunities. International Journal of Molecular Science, 18, E2078.

Cordeiro, M., Carlos, F. F., Pedrosa, P., Lopez, A., \& Baptista, P. V. (2016). Gold nanoparticles for diagnostics: Advances towards points of care. Diagnostics, 6, 43.

Costa, D., Razakandrainibe, R., Sautour, M., Valot, S., Basmaciyan, L., Gargala, G., ... \& Dalle, F. (2018). Human cryptosporidiosis in immunodeficient patients in France (20152017). Experimental Parasitoogy, 192, 108-112.

Cui, X., Xiong, Q. R., Xiong, Y. H., Shan, S., \& Lai, W. H. (2013). Establishing of a method combined immunomagnetic separation with colloidal gold lateral flow assay and its application in rapid detection of Escherichia coli O157:H7. Chinese Journal of Analytical Chemistry, 41, 1812-1816.

Dowd, A., Pissuwan, D., \& Cortie, M. B. (2014). Optical readout of the intracellular environment using nanoparticle transducers. Trends in Biotechnology, 32, 571-577. 
Du, J., Singh, H., Dong, W. J., Bai, Y. H., \& Yi, T. H. (2018). Colorimetric detection of Listeria monocytogenes using one-pot biosynthesized flower-shaped gold nanoparticles. Sensors and Actuators B: Chemical, 265, 285-292.

Du, X. J., Zhou, T. J., Li, P., \& Wang, S. (2017). A rapid Salmonella detection method involving thermophilic helicase-dependent amplification and a lateral flow assay. Molecular and Cellular Probes, 34, 37-44.

Duncan, C. L. (1970). Clostridium perfringens food poisoning. Journl of Milk and Food Technology, 33, 35-41.

Elghanian, R., Storhoff, J. J., Mucic, R. C., Letsinger, R. L., \& Mirkin, C. A. (1997). Selective colourimetric detection of polynucleotides based on the distance-dependent optical properties of gold nanoparticles. Science, 277, 1078 - 1080.

ESFA. (2017). The European Union summary report on trends and sources of zoonoses, zoonotic agents and food-borne outbreaks in 2016. European Food Safety Authority Journal, 15, 5077.

Eustis, S., El-Sayed, M. A. (2006). Why gold nanoparticles are more precious than pretty gold: noble metal surface plasmon resonance and its enhancement of the radiative and nonradiative properties of nanocrystals of different shapes. Chemical Society Reviews, 35, 209-217.

Fkiri, A., Mezni, A., Saber, N. B., Sellami, B., \& Smiri, L. S. (2017). Facile synthesis of gold nanoparticles with irregular shapes in polyol and aquatic ecotoxicity effects. Journal of the Tunisian Chemical Society 19, 288-293.

Fletcher, S., Boonwaat, L., Moore, T., Chavadac, R., \& Conaty, S. (2015). Investigating an outbreak of staphylococcal food poisoning among travellers across two Australian states. Western Pacific Surveillance and Response Journal, 6, 17-21.

Gao, S., Pearson, B., He, L. (2018). Mapping bacteria on filter membranes, an innovative SERS approach. Journal of Microbiological Methods, 147, 69-75.

Granum, P. E. (1990). Clostridium perfringens toxins involved in food poisoning. International Journal Food Microbiology, 10, 101-112.

Granum, P. E., \& Lund, T. (1997). Bacillus cereus and its food poisoning toxins FEMS Microbiology Letters, 157, 223-228.

Haddada, M. B., Salmain, M., \& Boujday, S. (2018). Gold colloid-nanostructured surfaces for enhanced piezoelectric immunosensing of staphylococcal enterotoxin A. Senors and Actuators B: Chemical, 255, 1604-1613.

Herizchi, R., Abbasi, E., Milani, M., \& Akbarzadeh, A. (2016). Current methods for synthesis of gold nanoparticles. Artificial Cells, Nanomedicine, and Biotechnology, 44, 596-602.

Hill, V. R., Cohen, N., Kahler, A. M., Jones, J. L., Bopp, C. A, Marano, N., .. \& Tauxe, R. V. (2011). Toxigenic Vibrio cholerae O1 in water and seafood, Haiti. Emerging Infectious Diseases, 17, 2147-2150.

Hinton, A. (2016). Growth of Campylobacter incubated aerobically in fumarate-pyruvate media or media supplemented with dairy, meat, or soy extracts and peptones. Food Microbiology, 58, 23-28.

Homola J. (2008). Surface plasmon resonance sensors for detection of chemical and biological species. Chemical Reviews, 108, 462-493.

Hounmanou, Y. M., Mdegela, R. H., Dougnon, T. V., Mhongole, O. J., Mayila, E. S., Malakalinga, J., Makingi, G., \& Dalsgaard, A. (2016). Toxigenic Vibrio cholerae O1 in vegetables and fish raised in wastewater irrigated fields and stabilization ponds during a non-cholera outbreak period in Morogoro, Tanzania: An environmental health study. BMC Research Notes, 20169, 466. 
Huang J., Zang X., Zhai W., Guan C., Lei T., \& Jiao X. (2018). Campylobacter spp. in chicken-slaughtering operations: a risk assessment of human campylobacteriosis in East China. Food Control, 86, 249-256.

Jemmi, T., \& Stephan, R. (2006). Listeria monocytogenes: food-borne pathogen and hygiene indicator. Review Science and Technology, 25, 571-580.

Kalluri, P., Crowe, C., Reller, M., Gaul, L., Hayslett, J., Barth, S., Eliasberg, S., Ferreira, J., Holt, K., Bengston, S., Hendricks, \& K., J. S. (2003). An outbreak of foodborne botulism associated with food sold at a salvage store in Texas. Cliical Infectious Disease, 37, 1490-1495.

Kim, Y. J., Kim, H. S., Chon. J. W., Kim, D. H., Hyeon, J. Y., \& Seo, K. H. (2018). New colorimetric aptasensor for rapid on-site detection of Campylobacter jejuni and Campylobacter coli in chicken carcass samples. Analytica Chimica Acta, 1029, 78-85.

Lanier, W. A., Hale, K. R., Geissler, A. L., \& Dewey, M. D. (2018). Chicken Liverassociated outbreaks of Campylobacteriosis and Salmonellosis, United States, 20002016: identifying opportunities for prevention. Foodborne Pathogens and Disease, 15, 726-733.

Li, F., Li. F., Yang. G., Aguilar. Z. P., Lai, W., Xu, H. (2018). Asymmetric polymerase chain assay combined with propidium monoazide treatment and unmodified gold nanoparticles for colorimetric detection of viable emetic Bacillus cereus in milk. Sensors and Actuators B: Chemical, 255, 1455-1461.

Li, Y. (2016). Establishment and application of a visual DNA microarray for the detection of food-borne pathogens. Analytical Science, 32, 215-218.

Li, C. Z., Vandenberg, K., Prabhulkar, S., Zhu, X., Schneper, L., Methee, K., Rosser, C. J., \& Almeide, E. (2011). Paper based point-of-care testing disc for multiplex whole cell bacteria analysis. Biosens Bioelectron,. 26, 4342-4348.

Liu, C. C., Yeung, C. Y., Chen, P. H., Yeh, M. K., \& Hou, S. Y. (2013). Salmonella detection using $16 \mathrm{~S}$ ribosomal DNA/RNA probe-gold nanoparticles and lateral flow immunoassay. Food Chemistry, 141, 2526-2532.

Liu, Y., Tam, Y. H., Yuan, J., Chen, F., Cai, W., Liu, J., Ma, X., ... \& Ip, D. (2015). A foodborne outbreak of gastroenteritis caused by Vibrio parahaemolyticus and Norovirus through non-seafood vehicle. Plos One, 10, e0137848.

Loir, Y. L., Baron, F., Gautier, M. (2003). Staphylococcus areus and food poisoning Genetics and Moleculr Research, 2, 63-67.

Ma, X., Song, L., Zhou, N., Xia, Y., \& Wang, Z. (2017). A novel aptasensor for the colorimetric detection of $\mathrm{S}$. typhimurium based on gold nanoparticles. International Journal of Food Microbiology, 245, 1-5.

Ma, X., Xu, X., Xia, Y., \& Wang, Z. (2018). SERS aptasensor for Salmonella typhimurium detection based on spiny gold nanoparticles. Food Control, 84, 232-237.

Martinović, T., Andjelković, U., Gajdošik, M. Š., Rešetar, D., \& Josić, D. (2016). Foodborne pathogens and their toxins. Journal of Proteomics, 147, 226-235.

Metz, Z. P., Ding, T., \& Baumler, D. J. (2018). Using genome-scale metabolic models to compare serovars of the foodborne pathogen Listeria monocytogenes. Plos One, 13, e0198584.

Mocan, T., Matea, C. T., Pop, T., Mosteanu, O., Buzoianu, A. D., Puia, C., Iancu, C., \& Mocan, L. (2017). Development of nanoparticle-based optical sensors for pathogenic bacterial detection. Nanobiotechnology, 15, 25.

Mohamed, S. D, \& Hadi, S. (2018). Applications of gold nanoparticles in virus detection. Theranostics, 8, 1985-2017. 
Niessen, L., Luo, J., Denschlag, C., \& Vogel, R. F. (2013). The application of loop-mediated isothermal amplification (LAMP) in food testing for bacterial pathogens and fungal contaminants. Food Microbiology, 36, 191e206.

Niu, S., Lv, Z., Liu, J., Bai, W., Yang, S., Chen, A. (2014). Colorimetric aptasensor using unmodified gold nanoparticles for homogeneous multiplex detection. PloS One, 9, e109263.

Oh, S. Y., Heo, N. S., Shukla, S., Cho, H. J., Vilian, A. T. E., Kim, J., Lee, S. Y., Han, Y. K., Yoo, S. M., \& Huh, Y. S. (2017). Development of gold nanoparticleaptamer-based LSPR sensing chips for the rapid detection of Salmonella typhimurium in pork meat. Science Report, 7,10130.

Pal, M., Merera, O., Abera, F., Rahman, M. T., \& Hazarika, R. A. (2015). Salmonellosis: A major foodborne disease of global significance. Beverage \& Food World, 42, 21-24.

Paramithiotis, S., Drosinos, H. E., \& Skansamis, N. P. (e.2017). Food recalls and warnings due to the presence of foodborne pathogens - a focus on fresh fruits, vegetables, dairy and eggs. Current Opinion in Food Science, 18, 71-75.

Pillsbury, A., Chiew, M., Bates, J., \& Sheppeard, V. (2013). An outbreak of staphylococcal food poisoning in a commercially catered buffet. Communical Diseases Intelligence, 37, E144-148.

Pissuwan, D., Hattori, Y. (2016). Detection of adhesion molecules on inflamed macrophages at early-stage using SERS probe gold nanorods. Nano-Micro Letters, 9: 8.

Pissuwan, D., Hobro, A. J., Pavillon, N., \& Smith, N. I. (2014). Distribution of label free cationic polymer-coated gold nanorods in live macrophage cells reveals formation of groups of intracellular SERS signals of probe nanoparticles. RSC Advances, 4, 55365541 .

Pollari, F., Christidis, T., Pintar, K. D. M., Nesbitt, A., Farber, J., Lavoie, M. C., Gill, A., Kirsch, P., \& Johnson, R. P. (2017). Evidence for the benefits of food chain interventions on $E$. coli $0157: \mathrm{H} 7 / \mathrm{NM}$ prevalence in retail ground beef and human disease incidence: a success story. Canadian Journal of Public Health, 108, e71-e78.

Purslow, P. (2016). Parasitic zoonoses present some risks with low-temperature cooking of pork. Meat Science, 119, 14-15.

Qian, X., Peng, X. H., Ansari, D. O., Yin-Goen, Q., Chen, G. Z., Shin, D. M., Yang, L., Young, A. N., Wang, M. D., \& Nie, S. (2008). In vivo tumor targeting and spectroscopic detection with surface-enhanced Raman nanoparticle tags. Nature Biotechnology, 26, 8390.

Saheb, E. J. (2018) The prevalence of parasitic protozoan diseases in Iraq, 2016. Karbala Internstional Journal of Modern Science, 4, 21-25.

Sakon, N., Sadamasu, K., Shinkai, T., Hamajima, Y., Yoshitomi, H., Matsushima, Y., Takada, R., Terasoma, F., Nakamura, A., Komano, J., Nagasawa, K., Shimizu, H., Katayama, K., \& Kimura, H. (2018). Foodborne outbreaks caused by human Norovirus GII.P17-GII.17- contaminated Nori, Japan, 2017. Emerging Infecious Diseases, 24, 920923.

Sala, M. R., Arias, C., Dominguez, A., Bartolomé, R., \& Muntada, J. M. (2009). Foodborne outbreak of gastroenteritis due to Norovirus and Vibrio parahaemolyticus. Epidemiololgy \& Infection, 137, 626-629.

Seo, D. J., Lee, M. H., Son, N. R., Seo, S., Lee, K. B., Wang, X., \& Choi, C. (2014). Seasonal and regional prevalence of norovirus, hepatitis A virus, hepatitis E virus, and rotavirus in shellfish harvested from South Korea. Food Control, 41, 178-184.

Singh, J., Sharma, S., \& Nara, S. (2015). Evaluation of gold nanoparticle based lateral flow assays for diagnosis of Enterbacteriaceaea members in food and water. Food Chemistry, 170, $470-483$. 
Slot, E., Zaaijer, H. L., Molier, M., Van den Hurk, K., Prinsze, F., \& Hogema, B. M. (2017). Meat consumption is a major risk factor for hepatitis E virus infection. PLOS ONE, 12, e0176414.

Song, C., Liu, C., Wu, S., Li, H., Guo, H., Yang, B., Qiu, S., Li, J., Liu, L., Zeng, H., Zhai. X., \& Liu, Q. (2016). Development of a lateral flow colloidal gold immunoassay strip for the simultaneous detection of Shigella boydii and Escherichia coli O157:H7 in bread, milk and jelly samples. Food Control, 59, 345-351.

Spina, R. A., Spampinato, V., Gilliland, D., Jimenez, I. O., \& Ceccone, G. (2017). Influence of different cleaning processes on the surface chemistry of gold nanoparticles. Biointerphases, 12, 031003.

Suria, M.S., Mohd Afendy, A. T., Noor Azlina M., \& Zamri, I. (2015). Lateral flow assay strip for detection of Escherichia coli O157:H7. International Food Research Journal, 22, 2587-2593.

Tewari, A., \& Abdullah, S. (2015). Bacillus cereus food poisoning: international and Indian perspective. Journal of Food Science and Technology, 52, 2500-2511.

Thiramanas, R., \& Laocharoensuk, R. (2016). Competitive binding of polyethyleneiminecoated gold nanoparticles to enzymes and bacteria: a key mechanism for low-level colorimetric detection of gram-positive and gram-negative bacteria. Microchimica Acta, 183, 389-396.

Turkevich, J. (1985). Colloidal gold. Part I.Historical and preparative aspects, morphology and structure. Gold Bulletin, 18, 86-91.

Uusitalo, S., Kögler, M., Välimaa, A. L., Popov, A., Ryabchikov, Y., Kontturi V, ...\& Hiltunen, J. (2016). Detection of Listeria innocua on roll-to-roll produced SERS substrates with gold nanoparticles. RSC Advances. 6, 62981-62989.

Velusamy, V., Arshak, K., Korostynska, O., Oliwa, K., \& Adley, C. (2010). An overview of foodborne pathogen detection: In the perspective of biosensors. Biotechnoogy Advances, 28, 232-254.

Verma, M. S., Rogowski, J. L., Jones, L., \& Gu, F.X. (2015). Colorimetric biosensing of pathogens using gold nanoparticles. Biotechnology Advances, 33, 666-680.

Villamizar, R. G., Fernández, J., Marín, L., Muñiz, J, González, I., \& Lombó, F. (2015). Multiplex detection of nine food-borne pathogens by MPCR and capillary electrophoresis after using a universal pre-enrichment medium. Frontiers in Microbiology, 6, 1194.

Wang, W., Liu, L., Song, S., Xu, L., Zhu, J., \& Kuang, H. (2017). Gold nanoparticle-based paper sensor for multiple detection of 12 Listeria spp. by P60-mediated monoclonal antibody. Food and Agricultural Immunology, 28, 274-287.

Wang, Y., \& Alocilja, E. C. (2015). Gold nanoparticle-labeled biosensor for rapid and sensitive detection of bacterial pathogens. Journal of Biological Engineering, 9, 16.

Warren, B. R., Parish, M. E., \& Schneider, K. R. (2006). Shigella as a foodborne pathogen and current methods for detection in food. Critical Reviews Food Science and Nutrition, 46, 551-567.

Wu, Y. N., Liu, X. M., Chen, Q., Liu, H., Dai, Y., Zhou, Y. J., Wen, J., Tang, Z. Z., \& Chen Y. (2018). Surveillance for foodborne disease outbreaks in China, 2003 to 2008. Food Control, 84, 382-388.

Xu, X., Ma, X., Wang, H., \& Wang, Z. (2018). Aptamer based SERS detection of Salmonella typhimurium using DNA-assembled gold nanodimers. Mikrochim Acta, 185, 325.

Yeni, F., Yavas, S., Alpas, H., \& Soyer, Y. (e.2016). Most common foodborne pathogens and mycotoxins on fresh produce: A review of recent outbreaks. Critical Reviews in Food Scence and Nutrition, 56, 1532-1544.

Yoo, S. M., \& Lee, S.Y. (2016). Optical biosensors for the detection of pathogenic microorganisms. Trends in Biotechnology, 34, 7-25. 
Yugo, D. M., \& Meng, X. J. (2013). Hepatitis E virus: foodborne, waterborne and zoonotic transmission. International Journal of Environmental Research and Public Health, 10, 4507-4533.

Zha, X., Li, M., \& Xu, Z. (2018). Detection of foodborne pathogens by surface enhanced Raman spectroscopy. Frontiers in Microbiology, 9, 1236.

Zhang, H. N., Hou, P. B., Chen, Y-Z., Ma, Y., Li, X.-P., Lv, H., Wang, M., Tan, H. L., Bi, Z. W. (e.2016). Prevalence of foodborne pathogens in cooked meat and seafood from 2010 to 2013 in Shandong province, China. Iran Journal of Public Health, 45, 1577-1585.

Zhao, Y., Jiang, X., Qu, Y., Pan, R., Pang, X., Jiang, Y., \& Man, C. (2017). Salmonella detection in powdered dairy products using a novel molecular tool. Journal of Dairy Science, 100, 3480-3496.

\section{FIGURES AND TABLES}

\section{Lists of Figures}

FIGURE 2 Representation of surface electrons of GNPs interacting with electromagnetic waves to induce localised surface plasmon resonance (LSPR) (Cordeiro et al., 2016). Reprinted with permission from Ref. (Cordeiro et al., 2016). Copyright(@2016 Multidisciplinary Digital Publishing Institute.

FIGURE 2 Schematic diagram showing the use of GNPs in various forms of biomedical applications.

FIGURE 3 Schematic illustration of the principle of detection in the two-stage aptasensor platform developed by Y.-J. Kim et al (Kim et al., 2018). Reprinted with permission from Ref. (Kim et al., 2018). Copyright@2018 Elsevier.

FIGURE 4 A schematic depiction of the principle of GNP-based LFA to target genomic DNA (invA gene) amplified by thermophilic HAD for Salmonella detection. The invA gene is labeled with digoxin and biotin (Du, Zhou, Li, \& Wang, 2017). Reprinted with permission from Ref. (Du, Zhou, Li, \& Wang, 2017). Copyright@2017 Elsevier.

FIGURE 5 The detection of $E$. coli $\mathrm{O} 157: \mathrm{H} 7$ by using GNPs-based LFAs. The strip only detects $E$. coli $\mathrm{O} 157: \mathrm{H} 7$ and produces the red color of GNPs at the control line (C) and the test line (T). In the case of Salmonella typhimurium (ST), Campylobacter jejuni (CJ), and Listeria monocytogenes (LM), the red color cannot be detected at the test line. Reprinted with permission from Ref. (Suria, Afendy,Azlina, \& Zamri, 2015). Copyright@2015 Universiti Putra Malaysia.

FIGURE 6 Schematic illustration of process to concentrate and detect E. coli 0157:H7 using immunomagnetic beads. (Top) Separation and concertation of target bacteria. (Bottom) GNP-based 
LFA for E. coli 0157:H7 detection. Reprinted with permission from Ref. (Cui et al., 2013). Copyright $\odot 2013$ Elsevier

FIGURE 7 Schematic overview of Salmonella typhimurium detection in samples using a GNPaptamer-based LSPR sensing chip with the property that absorbance is correlated with number of attached live bacteria. Reprinted with permission from Ref. (Oh et al., 2017). Copyright $\odot 2017$ Nature.

FIGURE 8 The overview of ALP labelled SERS active assay for Escherichia coli detection. Reprinted with permission from Ref. (Bozkurt et al., 2018). Copyright@2018 Elsevier.

FIGURE 9 SERS maps of surface of sensor for different concentrations of E. coli O157:H7. Reprinted with permission from Ref. (Gao, Pearson, \& He, 2018). Copyright@2018 Elsevier.

FIGURE 10 The schematics represents spiny GNPs and aptamer as a SERS nanoprobe to detect Salmonella typhimurium. Reprinted with permission from Ref. (Ma, Xu, Xia, \& Wang, 2018). Copyright@2018 Elsevier.

FIGURE 11 The schematics represent the combination of polyaniline capped MNPs conjugated with anti-E. coli $0157: \mathrm{H} 7$ monoclonal antibody to separate E. coli 0157:H7. The carbohydrate-coated GNPs conjugated anti-E. coli $0157: \mathrm{H} 7$ polyclonal antibody was applied to form a sandwich structure with MNPs and to enhance electrochemical signals. Reprinted with permission from Ref. (Wang \& Alocilja, 2015). Copyright@2015 BioMed Central.

FIGURE 12 The surface modification of (a) gold and (b) silicon substrates by using GNPs. (c) The treatment of GNPs by with cysteamine (CEA) and 1,4-phenylenediisothiocyanate (PDITC). Reprinted with permission from Ref. (Haddada, Salmain, \& Boujday, 2018). Copyright@2018 Elsevier.

FIGURE 13 The 'peace design' GNP-based-LFA format was used to distinguish target bacteria; Staphylococcus aureus in the mixed bacteria (S. aureus \& $P$. aeruginosa). (a) The sample contains only S. aureus, (b) The sample contains only P. aeruginosa and (c) the mixture of $S$. aureus and $P$. aeruginosa, were tested on GNPs-based Peace design LFA (Li et al., 2011).

FIGURE 14 The schematics represent GNP-based LFA for detection Escherichia coli O157:H7 and Salmonella boydii at one time. Reprinted with permission from Ref. (Song et al., 2016). 
Copyright@2016 Elsevier.

FIGURE 15 The red colors present on the strip after testing with the samples containing Salmonella boydii, Escherichia coli O157:H7, and the mixture of S. boydii and E. coli O157:H7. Reprinted with permission from Ref. (Song et al., 2016). Copyright@2016 Elsevier.

\section{Lists of Tables}

TABLE 1 Examples of pathogenic bacteria, viruses, and parasites that can contaminate food and cause foodborne diseases.

TABLE 2 The limit of detection for foodborne bacteria, for different techniques. 